\title{
Alteraciones histopatológicas causadas por la roya Puccinia nakanishikii (Pucciniales: Pucciniaceae) en plantas de Cymbopogon citratus (Poaceae)
}

\author{
Edgar Javier Rincón Barón ${ }^{1}$, Ana Mariany Gutiérrez Rodríguez ${ }^{2}$, Beatriz Elena Guerra ${ }^{1}$ \\ \& Silvia Espinosa Matías ${ }^{3}$ \\ 1. Universidad de Santander, Facultad de Ciencias de la Salud y Facultad de Ciencias Exactas Naturales y Agropecuarias, \\ Grupo de Investigación Agroambiente y Salud-MICROBIOTA, calle 70 No 55-210, Campus Universitario Lagos del \\ Cacique, Bucaramanga, Colombia; ed.rincon@mail.udes.edu.co, ejrbaron@gmail.com, bguerra@udes.edu.co \\ 2. Universidad Industrial de Santander, Bucaramanga, Colombia; mariany.biologa.uis@hotmail.com \\ 3. Laboratorio de Microscopía Electrónica de Barrido, Facultad de Ciencias, Universidad Nacional Autónoma de \\ México, Av. Universidad 3000, C.P. 04510, Ciudad de México, México; semfc2010@gmail.com
}

\section{Recibido 23-V-2019. Corregido 06-XI-2019. Aceptado 12-II-2020.}

\begin{abstract}
Histopathological alterations caused by Puccinia nakanishikii rust (Pucciniales: Pucciniaceae) in Cymbopogon citratus (Poaceae) plants. Introduction: Histopathological and histochemical aspects linked to the attack of fungal rusts to plants, as well as its relation with the different spore stages are topics rather scarce in the scientific literature. Objective: To describe and analyze the histopathological and histochemical aspects of Cymbopogon citratus and its relation with the different stages of the spores from the rust fungi Puccinia nakanishikii. Methods: During the months April and August 2013, leaves healthy and infected by Puccinia nakanishikii were collected in the Northwestern scarp of the Bucaramanga-Colombia plateau. The samples with injuries on diverse developmental stages were fixated and processed according to the standard protocols for embedding and sectioning in paraffin and resin. Sections obtained from paraffin (5-7 $\mu \mathrm{m})$ were stained with Safranin-Alcian blue and Alcian blue-Hematoxylin. On the other hand, sections obtained from resin $(0.5 \mu \mathrm{m})$ were stained with Toluidine blue. Further, freehand sections were obtained for an autofluorescence analysis. The observations and photographic record were done via photonic microscope and epifluorescence microscope. For the observations via scanning electron microscopy (SEM), the samples were fixated in Glutaraldehyde, dehydrated with 2,2 dimethoxypropane, then desiccated to critical point and finally coated with gold. Results: The leaves are generally hypostomatic, with long and short epidermic cell forming parallel rows and showing unicellular prickle trichomes and micro-trichomes. The abaxial surface is covered by epicuticular wax forming a dense layer. The adaxial epidermis is formed by groupings of bulliform cells and epidermal cells with rectangular or squared contour. In the mesophyll, there is no differentiation between palisade and spongy parenchyma, its anatomy reflects the $\mathrm{C}_{4}$ metabolism. The formation of uredosori and teliosori both hypophyllous was observed. Urediniospores are the reinfecting agents phase, they have 4-5 equatorial germ pores and echinulate wall. Teliospores have smooth wall and a persistent pedicel. The urediniospores form a germ tube, generally on the abaxial leaf surface, these tubes develop towards the stomata reaching the mesophyll interior. No appressorium were observed. The epidermis limiting the uredosorus detaches due the development and pressure that exert both the urediniospores and capitate paraphyses. As the infection progresses, autofluorescense of the chlorophyll is lost and the cells undergo necrotic processes. Afterwards, the phloem collapses and the xylem becomes slightly disorganized. At this moment, the infection is extended along the whole leaf blade, resulting in the leaf death and the plant defoliation. On advanced stages of the infection, the uredosori showed pycnidia, probably
\end{abstract}

Rincón Barón, E.J., Gutiérrez Rodríguez, A.M., Guerra, B.E., \& Espinosa Matías, S. (2020) Alteraciones histopatológicas causadas por la roya Puccinia nakanishikii (Pucciniales: Pucciniaceae) en plantas de Cymbopogon citratus (Poaceae). Revista de Biología Tropical, $68(2), 361-382$. 
belonging to the hyperparasite Sphaerellopsis, these structures were closely associated to the rust infected tissues. Conclusions: Puccinia nakanishikii develops on the leaves of Cymbopogon citratus producing uredosori and teliosori. Urediniospores are the reinfective stage, teliospores were only observed at late stages of the infection. The epidermis and photosynthetic tissue are severely affected by cell necrosis. The vascular tissues are deeply affected on the advances stages of the infection.

Key words: histopathology alterations, rust fungi, teliospores, ultrastructure, urediniospores.

Las royas (Pucciniales, Basidiomycetes) son un grupo de hongos fitopatógenos biótrofos obligados de mayor diversidad, distribución e importancia económica (Savile, 1984; Staples, 2000; Agrios, 2005; Singh et al., 2008; Voegele, Hahn, \& Mendgen, 2009). Están conformadas por 13 familias, 163 géneros y unas 7000 especies de distribución cosmopolita, excepto en los polos (Buriticá, 2001; Zuluaga, Buriticá, \& Marín, 2009; Hawksworth \& Lücking, 2017). Las royas macrocíclicas poseen la capacidad de generar cinco tipos de esporas funcionalmente diferentes en su ciclo de vida (espermacias, aeciosporas, teliosporas, urediosporas y basiodiosporas) y la posibilidad de parasitar uno o dos diferentes hospederos de grupos taxonómicos no relacionados para completar su ciclo de vida (Cummins \& Hiratsuka, 2003, Agrios, 2005; Webster \& Weber, 2007; Schumann \& D'Arcy, 2009; Zuluaga et al., 2009). Así mismo, las royas son los hongos que presentan la mayor diversidad de hospederos, incluyendo musgos, licófitos, helechos, gimnospermas y angiospermas (Pardo, 2003).

Las enfermedades ocasionadas por las royas son de las más devastadoras que se pueden presentar en plantas, causando reducción del follaje, disminución del crecimiento radicular, reducción de la tasa fotosintética y aumento de la tasa respiratoria (Doohan \& Zhou, 2018). Con lo cual, la producción por cosecha disminuye enormemente y lo poco que se puede aprovechar es de mala calidad nutricional; lo que afecta la producción de alimentos a nivel mundial (Epstein, Simons, Frey, \& Rothman, 1998; Leyva, Espitia, Villaseñor, \& Huerta, 2004; Agrios, 2005; Singh et al., 2008; Kolmer, Ordonez, \& Groth, 2009; Singh et al., 2016;
Bhattacharya, 2017; Carris \& Littlefield, 2017; Doohan \& Zhou, 2018).

Las royas afectan principalmente los cultivos de cereales, por ejemplo, la roya del trigo (Puccinia graminis Pers.), avena (Puccinia coronata Corda), centeno (Puccinia triticina Ericks.), sorgo (Puccinia purpurea Cooke.) y maíz (Puccinia sorghi Schwein.). Se estima que a nivel mundial anualmente se pierde $10 \%$ de las cosechas debido a la infección de estos fitopatógenos (Pavgi, 1972; Eversmeyer \& Kramer, 2000; Staples, 2000; Agrios, 2005; Singh et al., 2008; Zuluaga et al., 2009; Singh et al., 2016; Bhattacharya, 2017; Carris \& Littlefield, 2017; Doohan \& Zhou, 2018). Las enfermedades causadas por royas también han provocado grandes pérdidas en cultivos de algodón (Puccinia cacabata Arthur \& Holway), café (Hemileia vastatrix Berk \& Br.), pinos (Cronartium flaccidum Alb. \& Schwein.), manzanos (Gymnosporangium juniperi-virginianae Schwein.) y plantas ornamentales (Pardo, 1998; Salazar, Buriticá, \& Cadena, 2002; Agrios, 2005; Buriticá \& Salazar, 2007).

Tradicionalmente, la clasificación taxonómica de Pucciniales se ha basa en las características morfológicas, el tamaño y la ornamentación de la pared de las teliosporas, uredosporas y basiodiosporas (Cummins, 1971; Cummins \& Hiratsuka, 2003), y el tamaño y la forma del espermogonio (Hiratsuka \& Hiratsuka, 1980; Cummins \& Hiratsuka, 2003). Así mismo, se han hecho grandes esfuerzos para la determinación de las relaciones filogenéticas de las especies de royas utilizando diferentes marcadores moleculares (Maier, Begerow, Wei, \& Oberwinkle, 2003; Zuluaga et al., 2009; 
Dixon, Castlebury, Aime, Glynn \& Comstock, 2010; Zuluaga, Buriticá, \& Marín, 2011).

Los estudios de las royas en Colombia se iniciaron entre 1801 y 1803 con las observaciones hechas por Francisco José de Caldas en las que concluyó el origen parasitario del polvillo del trigo (Salazar et al., 2002; Zuluaga et al., 2009), posteriormente Mayor (1913) describió 158 especies de Pucciniales pertenecientes a 13 géneros de las cuales 84 fueron consideradas nuevas especies. Chardón y Toro (1930) reconocieron 610 especies, de las cuales, 44 se describieron como especies nuevas. A partir de la década de los setenta, Buriticá (1978, 1991, 2001, 2003) Pardo (1998, 2003), Salazar y Buriticá $(2003,2004,2008)$ y Salazar et al., (2002) centran su atención en trabajos taxonómicos, descriptivos y enfocados principalmente en plantas de importancia económica como las aromáticas, ornamentales y culinarias; logrando consolidar varios inventarios sobre la diversidad de Pucciniales en este país (Buriticá, 1978, 1991; Buriticá \& Pardo, 1996; Buriticá \& Salazar, 2007; García, Buriticá, \& Henao, 2007). En años recientes, Buriticá, Salazar y Pardo (2014) en una extensa revisión de las royas de Colombia registran 70 géneros distribuidos en 456 especies.

Cymbopogon citratus (DC.) Stapf es conocida comúnmente como limoncillo, es una hierba perenne procedente del sureste asiático distribuida globalmente en zonas tropicales y subtropicales (Pareek \& Gupta, 1985; Soto, Vega, \& Tamajón, 2002; Negrelle \& Gómez, 2007; Nelson, 2008; Scot, 2008). C. citratus pertenece a la familia Poaceae que incluye aproximadamente 11000 especies de amplia distribución y de importancia económica y ecológica (GPWG, 2012). Es una planta utilizada para la obtención de aceites esenciales, producción de celulosa, sílica y algunos óxidos metálicos (Guerra, Rodríguez, García, \& Rangel, 2004; Haque, Remadevi, \& Naebe, 2018) En Colombia se cultiva principalmente en los departamentos de Antioquia y Caldas con el fin de obtener citronela, un aceite esencial de amplio uso comercial y por el extenso y fibroso sistema radicular que posee la planta es utilizada como protector del suelo contra la erosión en la zona cafetera colombiana (Serrato \& Moreno, 2003). Varios factores afectan la producción de aceites esenciales a partir de esta planta, entre estos, uno de los más importantes es la infección producida por las royas del género Puccinia (Pers. ex Pers.). A nivel global dentro de las royas más importantes registradas por causar grandes daños en plantas de C. citratus se encuentran Puccinia nakanishikii Dietel., P. purpurea y Puccinia cymbopogonis Massee (Pardo, 1999; Vida, Carvalho, \& Verzignassi, 2006; Nelson, 2008; Melo, Araújo, Carvalho, Tostes, \& Arêas, 2010). En Colombia se indica la presencia de P. nakanishikii y P. cymbopogonis en C. citratus (Morales \& Salazar, 2014).

Los principales síntomas causados por estos tipos de roya en $C$. citratus son daños en las hojas. Las lesiones se presentan como manchas alargadas y de coloración pardo-rojizo oscuro, tanto en la cara adaxial como abaxial de las hojas, alcanzando hasta $0.5 \mathrm{~cm}$ de largo y con masas de esporas (Vida et al., 2006; Morales \& Salazar, 2014). A medida que avanza la infección, toda la planta puede llegar a tener este mismo color pardo, así como grandes manchas necróticas a lo largo de la superficie foliar, ocasionando la muerte de las plantas en etapas avanzadas de la infección, llevando a la devastación de los cultivos (Nelson, 2008).

Aunque se han hecho grandes avances en aspecto citológicos, bioquímicos y moleculares relacionados con la infección de las royas (Mendgen \& Hahn, 2002; Carver \& Gurr, 2006; Voegele et al., 2009; Voegele \& Mendgen, 2011). Los trabajos sobre los aspectos histopatológicos de las infecciones ocasionadas por estos hongos son pocos y la mayoría aborda el tema de forma superficial y poco detallada (Srivastava \& Abraham, 1977; Kloppers \& Piietorius, 1995; Bender, Pretorius, Kloppers, \& Spies, 2000; Hernandez \& Hennen, 2003; Moldenhauer, Moerschbacher, \& Westhuizen, 2006; García et al., 2007; Li, Windham, \& Trigiano, 2007; Jiang \& Kang, 2010; Wesp, Martinelli, Sganzerla, \& Soares, 2013; Wahyuno \& Kakishima, 2015). 
Por estas razones, en esta investigación se realizó una descripción pormenorizada de los aspectos histopatológicos y anatómicos de las hojas de $C$. citratus infectas con la roya $P$. nakanishikii. Detallando los efectos causados por el crecimiento y desarrollo de las hifas sobre la epidermis y los tejidos que constituyen el mesófilo foliar. Así mismo, se describen a nivel estructural y ultraestructural los estados espóricos encontrados en las hojas del hospedante. Con lo cual se presentan datos nuevos y originales sobre aspectos histológicos del hospedante relacionados con la infección y el ciclo de vida de la roya $P$. nakanishikii.

\section{MATERIALES Y MÉTODOS}

Las muestras de las hojas de C. citratus fueron recolectadas desde abril hasta agosto 2013 en época de lluvias y época seca respectivamente, en la escarpa noroccidental de la meseta de Bucaramanga-Colombia a $910 \mathrm{~m}$ de altitud $\left(7^{\circ} 08^{\prime} 47^{\prime \prime} \mathrm{N}-73^{\circ} 08^{\prime} 0384^{\prime \prime} \mathrm{W}\right)$. Las muestras incluyeron tanto hojas sanas como enfermas, con lesiones ocasionadas por P. nakanishikii en diferentes momentos del desarrollo. Los ejemplares de respaldo se depositaron en el Museo Micológico de la Universidad Nacional de Colombia, sede Medellín (MMUNM) con la clave 1 788. Las muestras sanas y enfermas de C. citratus se fijaron en una mezcla de formol, etanol y ácido acético (FAA) por 24-48 horas a $6{ }^{\circ} \mathrm{C}$, se cortaron en fragmentos de $1 \mathrm{~cm}$ de longitud, se deshidrataron en la serie gradual de alcoholes y aclaramiento en Xilol (Ruzin, 1999) y se incluyeron en Paraplast plus (Mc Cormick $\left.{ }^{\circledR}\right)$ durante 12 horas a $55^{\circ} \mathrm{C}$. Se obtuvieron secciones transversales con micrótomo rotatorio LEICA RM ${ }^{\circledR} 2125$, entre 5-7 $\mu \mathrm{m}$ de grosor. Finalmente, se procedió a la tinción de las muestras con Safranina-azul de Alcian y azul de Alcian-Hematoxilina. Para descripciones adicionales, algunas muestras se fijaron en Glutaraldehído al $2.5 \%$ en buffer fosfato, $\mathrm{pH}$ 7.2 y $0.2 \mathrm{M}$ durante $24-48$ horas a $6{ }^{\circ} \mathrm{C}$. Luego de la fijación, las muestras se lavaron en el mismo buffer y con agua destilada para luego postfijarlas con tetróxido de osmio al $2 \%$ por
4 horas a $6{ }^{\circ} \mathrm{C}$ en oscuridad y agitación constante. Posteriormente, se deshidrataron durante una hora en cada etapa de la serie de etanol y durante 12 horas en etanol al $100 \%$ a $6{ }^{\circ} \mathrm{C}$ y se embebieron en mezclas progresivas de óxido de propileno-resina Spurr, por una semana a temperatura ambiente. Se hicieron varios cambios de resina pura durante seis días en constante agitación. La resina fue polimerizada a $60{ }^{\circ} \mathrm{C}$ por 48 horas. Se obtuvieron secciones de $0.4-0.5 \mu \mathrm{m}$ con cuchillas de vidrio en ultramicrótomo Leica ${ }^{\circledR}$, que se tiñeron con azul de toluidina (TBO) en bórax al $1 \%$, pH 3.6 por 30-60 segundos (Ruzin, 1999; Yeung, Stasolla, Sumner, \& Huang, 2015).

Adicionalmente, se elaboraron secciones transversales de las hojas a mano alzada de material fresco sano y afectado por el patógeno, este material se observó sin teñir y con epifluorescencia, empleando filtro UV-2A con filtro de excitación de 330-380 nm y filtro barrera de $420 \mathrm{~nm}$.

Para llevar a cabo las descripciones morfológicas con MEB, el material vegetal infectado con $P$. nakanishikii se fijó en Glutaraldehído y se deshidrató en 2.2 dimetoxipropano (Lin, Falk, \& Stocking, 1977), posteriormente se efectuó el desecado a punto crítico con un desecador SAMDRI ${ }^{\circledR}-795$. Los fragmentos de las hojas se montaron sobre cinta conductiva de carbón de doble cara y se recubrieron con oro en una ionizadora DENTON VACUUM DESK IV ${ }^{\circledR}$ durante 5 minutos, y se observaron con un JEOL JSM-6490LV ${ }^{\circledR}$. En esta investigación las observaciones estructurales y microestructurales se enfocaron principalmente en la cara abaxial de la lámina foliar, mesófilo, haces vasculares y estados espóricos encontrados. Se procesaron las regiones mediales de las hojas maduras sanas y enfermas, en este último caso en las zonas donde se presenta la infección y las lesiones causadas por la roya.

Las secciones en resina y parafina se examinaron con un microscopio fotónico Nikon eclipse Ni equipado con sistema de contraste diferencial de interferencia (CDI). Las fotografías se obtuvieron con cámara digital Nikon 
DS-Fi1 ${ }^{\circledR}$ utilizando el programa NIS Elements versión 4.30 .02 de Nikon.

\section{RESULTADOS}

\section{Hojas y tejidos sanos de $C$. citratus}

C. citratus es una gramínea perenne, cespitosa, rizomatosa, de hojas acintadas, usualmente aromática (Fig. 1A). Las hojas de C. citratus presentan simetría dorsiventral con venación paralelodroma, las hojas son predominantemente hipostomáticas, es decir con estomas ubicados principalmente en la cara abaxial de la lámina foliar, formando filas paralelas entre sí (Fig. 1B). Los estomas son poco frecuentes en la cara adaxial de la lámina foliar. La epidermis abaxial está formada por una capa de células que forman largas filas paralelas en torno a las venas. Estas células pueden ser largas o cortas, y por lo general de contorno rectangular (Fig. 1B). Se observó la presencia de tricomas unicelulares espinosos, orientados formando filas paralelas. Estos tricomas se caracterizan por presentar una zona apical aguda y una base ensanchada (Fig. 1B). Los microtricomas bicelulares forman filas paralelas y estos se presentan distanciados unos de otros. Estos tricomas son cortos de una célula basal hinchada y una distal delgada. Las células de la epidermis abaxial se encuentran cubiertas por una capa de ceras epicuticilares que se disponen a manera de láminas o escamas cortas densamente empaquetadas y que cubren profusamente a los estomas (Fig. 1C).

El mesófilo de la lámina foliar no está claramente diferenciado entre parénquima de empalizada y parénquima esponjoso (Fig. 1D, Fig. 1E). Las células parenquimatosas cercanas a la cara abaxial de la lámina foliar son pequeñas y con abundantes cloroplastos; en tanto que las del lado adaxial son más grandes y con una vacuola que ocupa la mayor parte del volumen celular (Fig. 1D, Fig. 1E). La densa distribución de los cloroplastos en estos tejidos se evidenció por su autofluorescencia en la longitud de onda correspondiente al rojo, al observar las secciones a mano alzada y con luz UV
(Fig. 1E). Tanto la epidermis adaxial como la abaxial presentan autofluorescencia en la longitud de onda de emisión del azul, al igual que el xilema y el esclerénquima. La mayoría de los tejidos parenquimátosos no fotosintéticos también presentan autofluorescencia y paredes ligeramente engrosadas que reaccionan con la Safranina produciendo un color rojo, indicando parcial lignificación (Fig. 1E). Se observaron haces vasculares colaterales cerrados de mayor y menor diámetro; los de mayor diámetro están recubiertos por una vaina esclerenquimática y soportados por columnas de este mismo tejido que se proyectan hasta la epidermis adaxial y abaxial adosándose a pequeñas células epidérmicas de contorno cuadrado o papilares de paredes engrosadas (Fig. 1D, Fig. 1E). En estos haces vasculares se observó grandes elementos metaxilemáticos asociados con protoxilema (Fig. 1E). Los haces vasculares de menor diámetro están rodeados por una vaina parenquimática monoestratificada radial que presenta cloroplastos en disposición centrifuga típico de la anatomía Kranz o C4 (Fig. 1F, Fig. $1 \mathrm{G})$. Cada uno de estos haces vasculares esta soportado por una columna de esclerénquima que se une a la epidermis abaxial. Estos haces vasculares generalmente presentan solo protoxilema (Fig. 1F). Los estomas son superficiales y se comunican con los tejidos internos a través de una amplia cavidad subestomática que se forma en el tejido parenquimatoso subyacente (Fig. 1F, Fig. 1G). Las células de la epidermis adaxial forman agrupaciones irregulares de células buliformes, separadas por agrupaciones de células epidérmicas pequeñas de contorno cuadrado y de paredes engrosadas que se asocian al tejido esclerenquimático (Fig. 1D, Fig. 1F).

\section{Hojas infectadas, estados espóricos y aspectos histopatológicos}

Los síntomas iniciales de la infección se manifiestan como manchas de color amarillento y progresan a un color marrón a medida que se desarrollan los urediosoros con masas de esporas. Posteriormente, con el avance del 

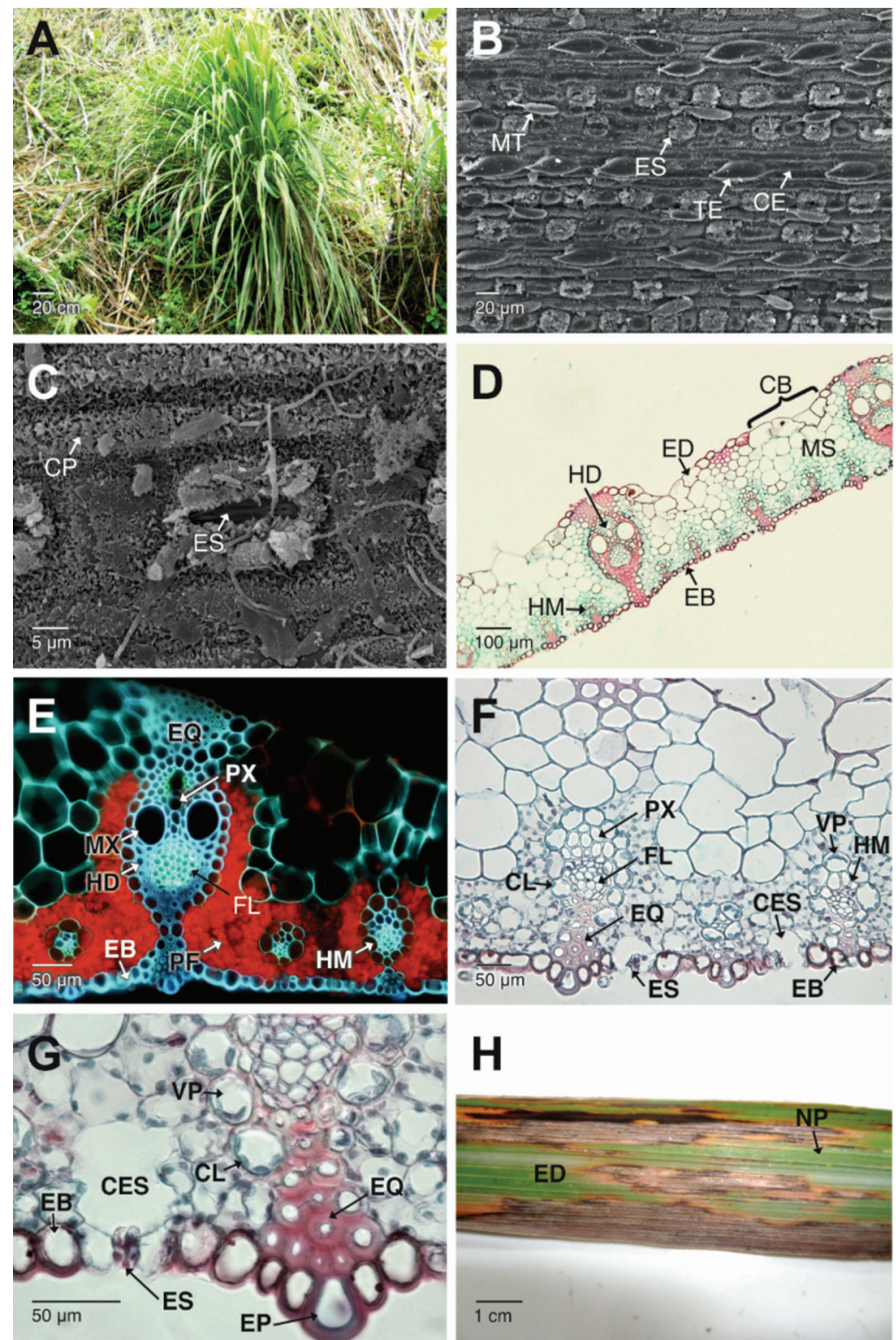

Fig. 1. Plantas, tejidos sanos y lesiones ocasionadas por Puccinia nakanishikii en Cymbopogon citratus. A. Planta cespitosa de C. citratus. B-C. Detalles de la cara abaxial de las hojas, mostrando el arreglo lineal de las células epidérmicas y sus derivados. D. Sección trasversal de las hojas. Se aprecia el mesófilo y los haces vasculares colaterales de mayor y menor diámetro (campo claro, Safranina-Azul de Alcian). E. Corte transversal a mano alzada de la hoja mostrando la epidermis adaxial, abaxial, haces vasculares y mesófilo de las hojas (cortes sin teñir y epifluorescencia filtro UV). F-G. Cortes transversales de la hoja mostrando la anatomía Kranz, estomas, cavidades subestomáticas y células epidérmicas adaxiales y abaxiales. H. Cara adaxial de la hoja mostrando lesiones y necrosis de los tejidos.

CB: células buliformes; CE: células epidérmicas; CES: cavidad subestomática; CL: cloroplastos; CP: ceras epicuticulares; EB: epidermis abaxial; ED: epidermis adaxial; EP: células epidérmicas papilares; EQ: esclerénquima; ES: estomas; FL: floema; HD: haces vasculares de mayor diámetro; HM: haces vasculares de menor diámetro; MS: mesófilo; MT: microtricomas; MX: metaxilema; NP: venación paralelódroma; PF: parénquima fotosintético; PX: protoxilema; TE: tricoma espinoso; VP: vaina parenquimatosa. 
daño celular, las lesiones se tornan marrón oscuro o negras. Estas lesiones son alargadas y coinciden con el patrón de venación de las hojas y orientación de los estomas (Fig. 1H). Las lesiones son visibles tanto en la cara adaxial como en la cara abaxial de la lámina foliar. A medida que la enfermedad se desarrolla las lesiones tisulares se expanden por toda la hoja llevando a la muerte prematura de la misma y defoliación de la planta.

Las pústulas que se observan sobre la cara abaxial de la lámina foliar corresponden a urediosoros que se orientan de forma paralela en el mismo sentido de los estomas y demás células epidérmicas (Fig. 2A). En los urediosoros se observan masas de urediosporas ovadas u obovoides de pared equinulada, sostenidas por una célula pedicelar y con 4-5 poros germinativos en posición ecuatorial (Fig. 2B, Fig. 2D). Entre las masas de urediosporas se observan paráfisis capitadas rectas (Fig. 2E). Los teliosoros solo se observaron en estados avanzados de la infección, estos son hipófilos y de color marrón oscuro (Fig. 2F), con teliosporas elipsoides de pared lisa y pedicelo persistente de color marrón pálido (Fig. 2G). Las urediosporas son la fase reinfecctante de la roya, estas se unen principalmente a la cara abaxial de la lámina foliar formando un pad o almohadilla de adhesión que se evidencia por la degradación de las ceras epicuticulares en este punto (Fig. $2 \mathrm{H})$. La urediospora germina y el tubo de germinación se desarrolla de forma perpendicular a las células epidérmicas (Fig. 3A). El tubo germinativo se puede ramificar y a medida que se desarrolla degrada las ceras epicuticulares a su paso (Fig. 3B). Finalmente, el tubo germinativo alcanza el estoma y penetra a través del ostiolo para alcanzar la cavidad subestomática y colonizar el mesófilo foliar (Fig. 3C). En los preparados observados no fue posible la observación de apresorios. Una vez dentro del mesófilo, las hifas parasitan primero a los tejidos fotosintéticos y se inicia la formación de un nuevo urediosoro (Fig. 3D). A medida que las urediosporas y las paráfisis capitadas crecen y desarrollan ejercen presión sobre la epidermis que se va levantando progresivamente hasta desprenderse (Fig. 3E, Fig. 3F). El desarrollo de las urediosporas inicia con la diferenciación de una hifa que forma la célula pedicelar y la célula inicial de la urediospora. Las urediosporas inmaduras presentan una pared delgada translucida que permite la observación de los dos núcleos característicos del estado dicarionte, pero a medida que la pared se engrosa y desarrolla, los núcleos se hacen menos conspicuos (Fig. 3F, Fig. 3H). El urediosoro, prosigue su desarrollo, con lo cual se forman nuevas urediosporas que son liberadas y terminan colonizando otras áreas en la hoja, formando nuevos urediosoros (Fig. 3H, Fig. 4A).

Los tejidos fotosintéticos inmediatamente debajo del urediosoro se ven fuertemente afectados, las células se van desorganizando y colapsando progresivamente hasta experimentar desorganización del citoplasma y perdida de la integridad de la pared celular y por último la muerte de tejidos (Fig. 4B). Para esta etapa de la infección los cloroplastos han colapsado y se evidencia el depósito progresivo de polifenoles en el citoplasma y paredes celulares primarias.

Fig. 1. Plants, healthy tissues and injures caused by Puccinia nakanishikii on Cymbopogon citratus. A. Caespitose plant of C. citratus. B-C. Details of the abaxial leaf surface showing the lineal arrangement of the epidermal cells and its derivatives. D. Cross section of the leaf blade showing the mesophyll and collateral vascular bundles of long and short diameter (bright field, Safranin-Alcian blue). E. Freehand cross section of the leaf blade showing the adaxial and abaxial epidermis, vascular bundles and mesophyll (unstained section and epifluorescence UV filter). F-G. Cross sections of the leaf showing the Kranz anatomy, substomatal cavities, adaxial and abaxial epidermic cells. H. Adaxial side of the leaf blade where injured and necrotic tissues are visible.

CB: bulliform cells; CE: epidermic cells; CES: substomatal cavity; CL: chloroplasts; CP: epicuticular waxes; EB: abaxial epidermis; ED: adaxial epidermis; EP: papillary epidermic cells; EQ: sclerenchyma; ES: stomata; FL: phloem; HD: long diameter vascular bundles; HM: short diameter vascular bundles; MS: mesophyll; MT: micro-trichomes; MX: metaxylem; NP: parallel venation; PF: photosynthetic parenchyma; PX: protoxylem; TE: prickle trichome; VP: parenchymatous sheath. 

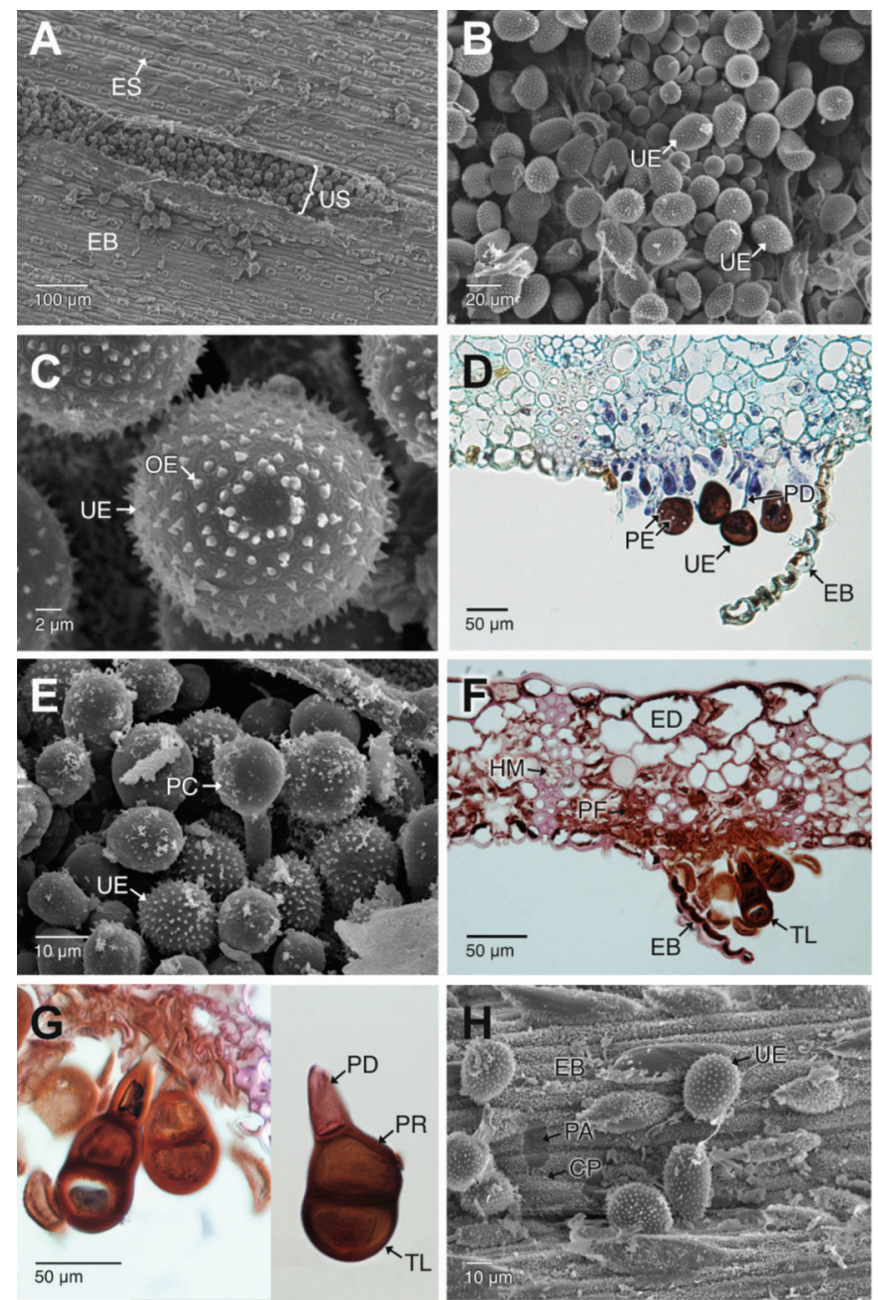

Fig. 2. Estados espóricos de Puccinia nakanishikii en Cymbopogon citratus. A-B. Urediosoros sobre la cara abaxial de la hoja. Se aprecian las masas de urediosporas. C. Detalle de las urediosporas. D. Sección transversal de un urediosoro. Se aprecian las urediosporas con poros germinativos ecuatoriales (campo claro, azul de Alcian-Hematoxilina.). E. Paráfísis capitada en los urediosoros. F-G. Secciones trasversales de un teliosoro y detalles de las teliosporas. Se aprecia el poro germinativo lateral de las teliosporas (campo claro, Safranina-azul de Alcian). H. Parche de adhesión de las urediosporas en la epidermis abaxial. Se observa la degradación de las ceras epicuticulares.

CP: ceras epicuticulares; EB: epidermis abaxial; ED: epidermis adaxial; ES: estomas; HM: haces vasculares de menor diámetro; OE: ornamentación equinulada; PA: parche de adhesión; PC: paráfisis capitadas; PD: pedicelo; PE: poros germinativos ecuatoriales; PF: parénquima fotosintético; PR: poro de germinación; TL: teliospora; UE: urediosporas; US: urediosoro.

Fig. 2. Sporal stages of Puccinia nakanishikii in Cymbopogon citratus. A-B. Uredosori over the abaxial face of the leaf blade. Masses of urediniospores are visible. C. Detail of the urediniospores. D. Cross section of the uredosorus. The urediniospores bearing equatorial germinative pores can be noticed (bright field, Alcian blue-Hematoxylin.). E. Capitate paraphysis on the uredosorus. F-G. Cross section of a teliosorus and details of the teliospores. The equatorial germ pores are visible on the teliospores (bright field, Safranin-Alcian blue). H. Adhesion patch of the urediniospores on the abaxial epidermis. Degradation of the epicuticular waxes is visible.

CP: epicuticular waxes; EB: abaxial epidermis; ED: adaxial epidermis; ES: stomata; HM: short diameter vascular bundles; OE: echinulate ornamentation; PA: adhesion patch; PC: capitate paraphyses; PD: pedicel; PE: equatorial germ pores; PF: photosynthetic parenchyma; PR: germ pores; TL: teliospore; UE: urediniospores; US: uredosori. 

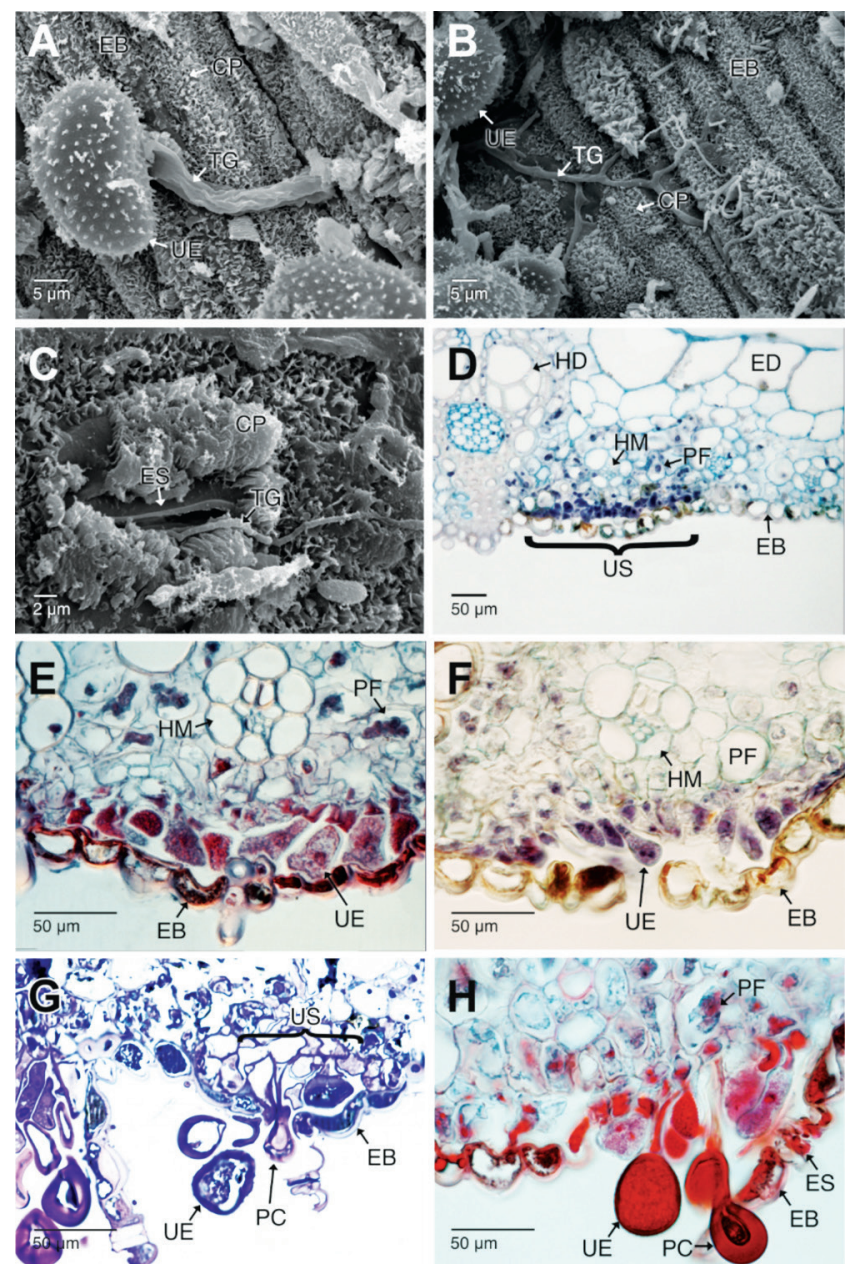

Fig. 3. Germinación de las urediosporas de Puccinia nakanishikii en la cara abaxial de Cymbopogon citratus y formación de los urediosoros. A-B. Espora germinando, se observa el tubo germinativo. C. Tubo germinativo entrando a los tejidos foliares a través de los estomas. D. Sección transversal de un urediosoro inmaduro en la cara abaxial de la hoja (campo claro, azul de Alcian-Hematoxilina). La tinción azul oscura indica la presencia de gran cantidad de núcleos celulares por la proliferación de las hifas. E-F. Secciones transversales de un urediosoro en desarrollo. Se aprecia el estado dicarionte (Safranina-azul de Alcian y azul de Alcian-Hematoxilina, respectivamente). G-H. Urediosoro levantando la epidermis abaxial. Se aprecia el efecto de la presión que ejercen las paráfisis capitadas en el proceso de levantar y romper la epidermis (Secciones transversales, campo claro, azul de toluidina y Safranina-azul de Alcian, respectivamente).

CP: ceras epicuticulares; EB: epidermis abaxial; ED: epidermis adaxial; ES: estomas; HD: haces vasculares de mayor diámetro; HM: haces vasculares de menor diámetro; PC: paráfisis capitadas; PF: parénquima fotosintético; TG: tubo germinativo; UE: urediosporas; US: urediosoro.

Fig. 3. Germination of urediniospores from Puccinia nakanishikii on the abaxial surface of Cymbopogon citratus and urediosoral development. A-B. Germinating spore showing the germ tube. C. Germ tube entering foliar tissues via the stoma. D. Cross section of an immature uredosorus on the leaf abaxial surface. (bright field, Alcian blue-Hematoxylin). The deep blue stain indicates presence of abundant cell nuclei due the hyphal proliferation. E-F. Cross section of a developing uredosori. Dikaryotic stage is visible (Safranin-Alcian blue and Alcian blue-Hematoxylin respectively). G-H. Uredosorus raising the abaxial epidermis. Notice the effect of the pressure exerted by the capitate paraphyses during the process of raising and rupture the epidermis (Cross sections, bright field, Toluidine blue and Safranin-Alcian blue respectively).

CP: epicuticular waxes; EB: abaxial epidermis; ED: adaxial epidermis; ES: stomata; HD: large diameter vascular bundles; HM: short diameter vascular bundles; PC: capitate paraphyses; PF: photosynthetic parenchyma; TG: Germ tube; UE: urediniospores; US: uredosori. 

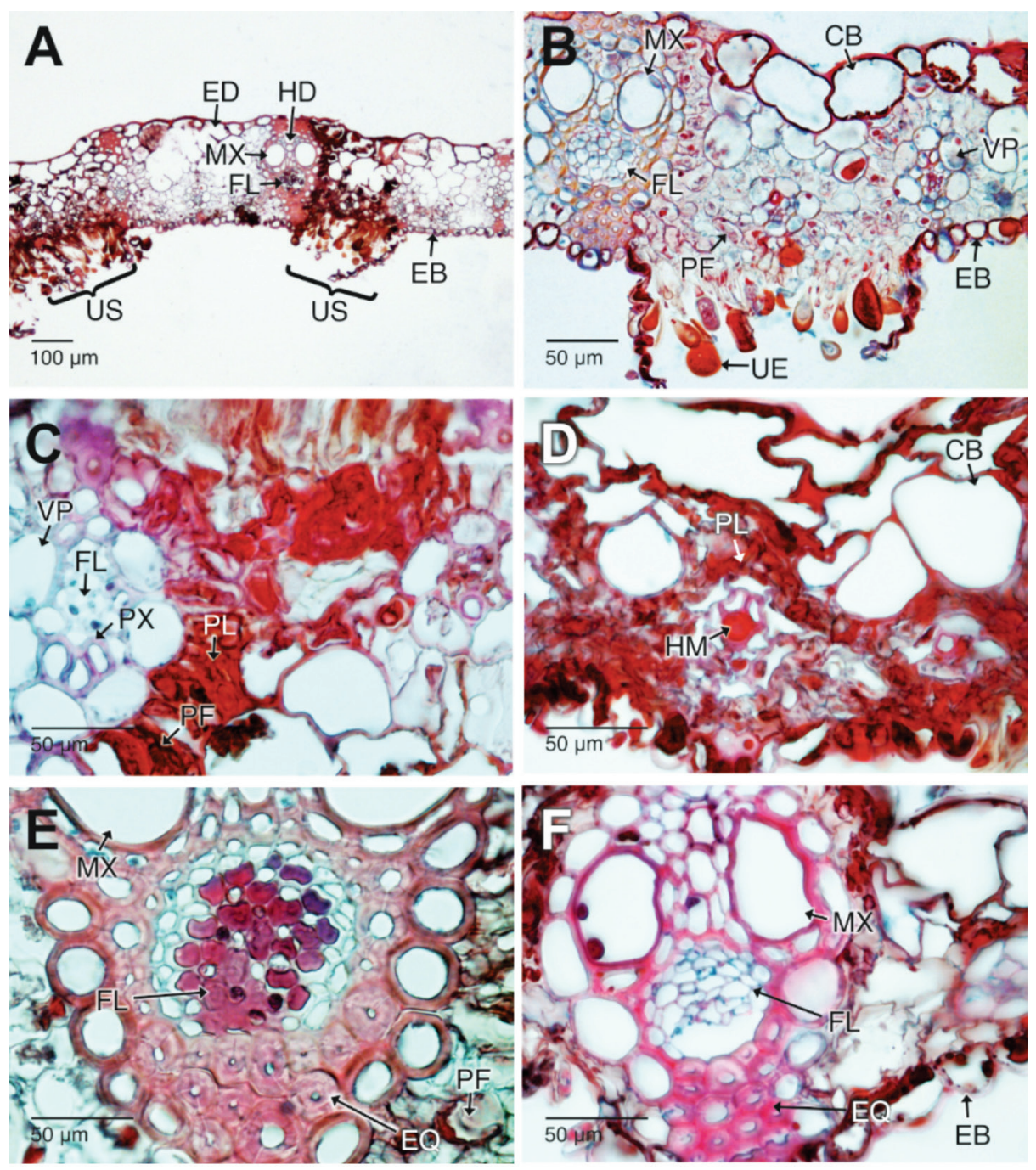

Fig. 4. Uredisoros maduros de Puccinia nakanishikii y aspectos histopatológicos en las hojas de Cymbopogon citratus (Secciones trasversales en campo claro, Safranina-azul de Alcian). A. Los urediosoros se desarrollan sobre toda la lámina foliar. B. Detalle de un urediosoro maduro. Se aprecian las masas urediosporas y el daño a los tejidos fotosintéticos, así mismos, los daños en los tejidos del lado adaxial de la lámina foliar. C-D. Detalle del colapso, necrosis y acumulación de polifenoles de los tejidos del mesófilo y epidermis adaxial de la hoja. E. Necrosis en el floema. F. Colapso del floema y deterioro leve del xilema.

CB: células buliformes; EB: epidermis abaxial; ED: epidermis adaxial; EQ: esclerénquima; FL: floema; HD: haces vasculares de mayor diámetro; HM: haces vasculares de menor diámetro; MX: metaxilema; PF: parénquima fotosintético; PL: polifenoles; PX: protoxilema; UE: urediosporas; US: urediosoro; VP: vaina parenquimatosa.

Fig. 4. Mature uredosori of Puccinia nakanishikii and histopathological aspects of the leaves from Cymbopogon citratus (cross sections in bright field, Safranin-Alcian blue). A. The uredosori develop over the whole leaf blade. B. Detail of a mature uredosorus. Visible are the mass of urediniospores and the damage to the photosynthetic tissues are appreciated, as well as the damages in the tissues of the adaxial side of the leaf blade. C-D. Detail of the collapse, necrosis and polyphenol accumulation on the tissues belonging to the mesophyll and adaxial epidermis of the leaf blade. E. Necrosis of the phloem. F. Collapse of the phloem and slight deterioration of the xylem.

CB: bulliform cells; EB: abaxial epidermis; ED: adaxial epidermis; EQ: sclerenchyma; FL: phloem; HD: short diameter vascular bundles; MX: metaxylem; PF: photosynthetic parenchyma; PL: polyphenols; PX: protoxylem; UE: urediniospores; US: uredosori; VP: parenchymatous sheath. 
Así mismo, las células buliformes y el resto de las epidérmicas de la cara adaxial también sufren estos procesos de deterioro celular hasta morir (Fig. 4C, Fig. 4D). En estados avanzados de la infección, la necrosis y muerte de los tejidos se hacen evidentes en los haces vasculares, afectando fuertemente al floema, en este se aprecia coagulación o precipitación del citoplasma. En tanto que en el xilema la pared lignificada se observa con insipientes ondulaciones (Fig. 4E, Fig. 4F, Fig. 5A). Rápidamente toda la hoja se va deteriorando y la necrosis y colapso celular avanza por la lámina foliar (Fig. 5B).

En las secciones de material fresco, y no teñidas, en las zonas no afectas por el crecimiento de la roya, los tejidos conservan su integridad celular y color verde por la presencia de los cloroplastos. Al observar estas mismas secciones con luz ultravioleta, se observó autofluorescencia roja en los tejidos fotosintéticos, debido a la presencia de clorofila en los cloroplastos. Por el contrario, las zonas afectadas por infección, se aprecian de color marrón oscuro debido a la necrosis celular causada por el patógeno (Fig. 5C). Las zonas necróticas no presentan autofluorescencia, lo que implica daño en los cloroplastos y degradación de la clorofila (Fig. 5D).

Asociados a los urediosoros maduros se observaron conidiomas tipo picnidios, probablemente del hongo hiperparásito, Sphaerellopsis Cooke (Fig. 5E). Los picnidios son negros, subglobosos y con un ostiolo apical en posición central, por donde se liberan masas de picnidiosporas (Fig. 5F). Estas estructuras de reproducción asexual son hialinas, de pared lisa, de contorno fusiforme-elipsoidal, de ápice subobtuso y se aprecian en grandes cantidades en los urediosoros (Fig. 5F, Fig. 5G). Los picnidios se ven estrechamente adheridos al mesófilo justo donde se encuentran las hifas del urediosoro que parasitan los tejidos fotosintéticos del hospedante (Fig. 5H).

\section{DISCUSIÓN}

En investigaciones previas se ha determinado que las hojas de C. citratus son principalmente hipostomáticas de simetría dorsiventral, con estomas de amplias cavidades subestomáticas formando filas paralelas a las venas, y tricomas espinosos unicelulares, así como, microtricomas bicelulares, y densas ceras epicuticulares principalmente sobre la superficie abaxial; en tanto que la superficie adaxial está formada principalmente por agrupaciones de células buliformes y células epidérmicas alargadas o cortas de contorno rectangular a cuadrado en sección trasversal y con escasos tricomas (Metcalfe, 1960; Bertea \& Maffei, 2010; Eltahir \& Abuereish, 2010; Shah, Kaur, Dhabiliya, \& Shri, 2012; Kellogg, 2015). Estas características de las hojas descritas por estos autores son similares a lo observado en esta investigación para $C$. citratus, aunque con ligeras diferencias, como la presencia ocasional estomas sobre la superficie adaxial de la lámina foliar. No obstante, se debe tener en cuenta que pequeñas variaciones entre las descripciones de uno $u$ otro autor se podrían relacionar con el lugar exacto de las hojas donde se realizaron las secciones, el número de muestras analizadas o incluso el estado de desarrollo de las hojas. Metcalfe, (1960), Bertea y Maffei (2010) y Kellogg (2015) indican la falta de diferenciación entre el parénquima de empalizada y el esponjoso de las hojas de C. citratus, así como las diferencias relacionadas con el mayor tamaño de las células parenquimatosas no fotosintéticas de la cara adaxial; estas observaciones son congruentes con los hallazgos registrados en esta investigación. Estas células parenquimatosas carecen de inclusiones citoplasmáticas, al parecer esta situación permitiría el paso de luz hacia las células parenquimatosas fotosintéticas presentes en la cara abaxial de la lámina foliar.

Las características anatómicas observadas en $C$. citratus en relación con el metabolismo 

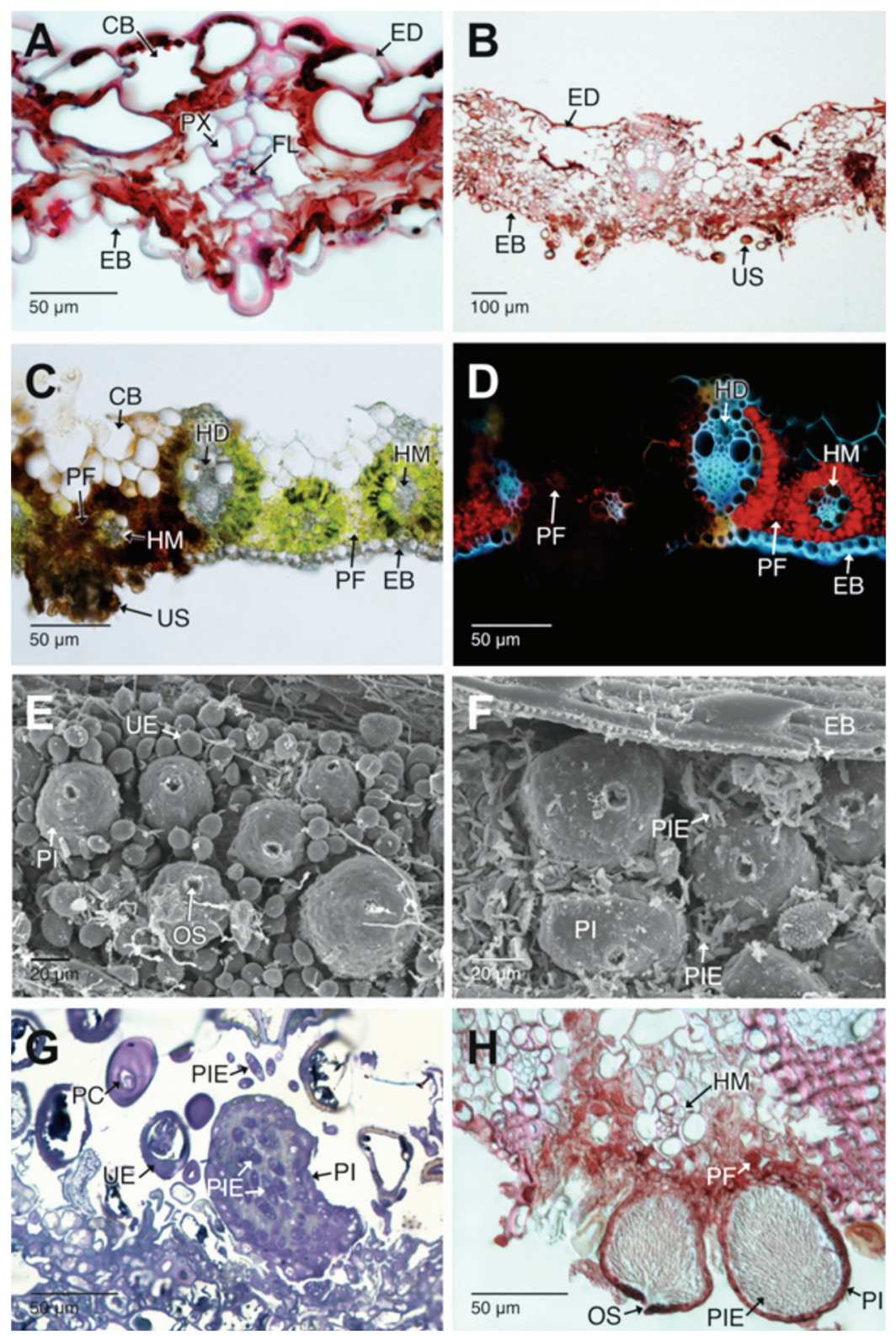

Fig. 5. Aspectos histopatológicos en las hojas de Cymbopogon citratus afectadas por Puccinia nakanishikii y picnidios con picnidiosporas del hiperparásito Sphaerellopsis. A-B. Secciones trasversales de las hojas necróticas. Con la evolución de la necrosis celular, todos los tejidos de la lámina foliar colapsan, persistiendo los haces vasculares colaterales de mayor diámetro (campo claro y con Safranina-azul de Alcian). C-B. Secciones transversales a mano alzada de un urediosoro (campo claro, sin teñir y epifluorescencia con luz UV, respectivamente). C. Los tejidos necróticos se aprecian en color marrón oscuro y los sanos en color verde. D. Los tejidos fotosintéticos sanos emiten autofluorescencia en rojo; los tejidos necrosados no presentan esta emisión. E-F. Detalle de los picnidios y picnidiosporas libres de Sphaerellopsis. G-H. Secciones longitudinales de los picnidios. G. Se aprecian las picnidiosporas (campo claro, azul de Toluidina). H. Se aprecia la estrecha unión entre los picnidios y los tejidos afectados por la roya (campo claro, Safranina azul de Alcian).

CB: células buliformes; EB: epidermis abaxial; ED: epidermis adaxial; ES: estomas; FL: floema; HD: haces vasculares de mayor diámetro; HM: haces vasculares de menor diámetro; OS: ostiolo; PC: paráfisis capitadas; PF: parénquima fotosintético; PI: picnidios; PIE: picnidiosporas libres; PX: protoxilema; UE: urediospora; US: urediosoro. 
$\mathrm{C}_{4}$ o Kranz característico de esta gramínea y la cual es consistente con la presencia de una banda uniestratificada radial de parénquima fotosintético con cloroplastos en posición centrifuga, principalmente alrededor de los haces vasculares de menor diámetro, es congruente con lo registrado en la literatura para esta especie y otras monocotiledóneas que tienen este mismo tipo de metabolismo (Metcalfe, 1960; Bertea et al., 2003; Bertea \& Maffei, 2010; Eltahir \& Abuereish, 2010; Shah, Kaur, Dhabiliya, \& Shri, 2012; Lundgren, Osborne, \& Christin, 2014; Kellogg, 2015).

Buckley, Sack y Gilbert (2011) determinaron que las hojas heterobáricas presentan una conexión hidráulica directa entre el tejido vascular y la epidermis, facilitando y permitiendo a los estomas una respuesta rápida a la disponibilidad del agua. Así mismo, dividiendo a las hojas en compartimentos funcionales que pueden afectar su estructura y función que bajo determinadas circunstancias favorecería un tipo determinado de anatomía. En este sentido, Torres, Silva, Nogueira, Alvarenga y Silva (2016) encontraron que las hojas heterobáricas son frecuentes en lugares de alta radiación solar y temperatura, por el contario las hojas homobáricas son más frecuentes en ambientes de baja radiación solar y alta humedad. Las hojas tipo heterobáricas, y con metabolismo $\mathrm{C}_{4}$ de $C$. citratus podrían favorecer el crecimiento de estas plantas en las duras condiciones tropicales donde normalmente se cultivan. No obstante, para darle apoyo a esta hipótesis, sería necesario realizar esta clase de investigaciones en monocotiledóneas sometidas a condiciones climáticas similares a la especie de estudio, dado que la mayoría de las investigaciones fisiológicas y anatómicas de hojas, hasta el momento están principalmente restringidas a dicotiledóneas (Kellogg, 2015).

Las lesiones por P. nakanishikii y la forma en que estas se desarrollan en las hojas de $C$. citratus, son similares a las registradas por esta misma especie de materiales procedente de varias regiones del mundo donde esta roya afecta de manera drástica los cultivos (Pardo, 1999; Ploetz, Palmateer, Lopez, \& Aime, 2013; Nelson, 2008; Morales \& Salazar, 2014). Sin embargo, las lesiones causadas por las tres especies de royas $P$. nakanishikii, P. purpurea y $P$. cymbopogonis que más afectan a los cultivos de esta planta aromática, son muy similares; por tal razón, para su identificación exacta se hace necesaria la revisión microscópica para detallar caracteres taxonómicos como son la posición de los poros germinativos de las urediosporas y la forma y presencia de paráfisis capitadas (Gardner, 1985; Koike \& Molinar, 1999; Melo et al., 2010; Morales \& Salazar, 2014). Las observaciones hechas en esta investigación corroboran la circunscripción del material fúngico con la especie $P$. nakanishikii.

En trabajos previos se ha evidenciado que los urediosoros formados por P. nakanishikii en las hojas de C. citratus son hipófilos y erupentes, formando líneas paralelas entre sí que coinciden con la disposición de las estomas que son los sitios por donde entra el tubo germinativo. Así mismo, las urediosporas se han descrito como ovadas, de pared equinulada, con 4-5 poros germinativos en posición ecuatorial;

Fig. 5. Histopathological aspects of the leaves from Cymbopogon citratus affected by Puccinia nakanishikii and pycnidia with pycnidiospores of the hyperparasite Sphaerellopsis. A-B. Cross sections of the necrotic leaves. As the cell necrosis progresses, all the tissues in the leaf blade collapse, the collateral vascular bundles of longer diameter persist. (bright field and Safranin-Alcian blue). C-B. Freehand cross-sections of a uredosorus (bright field, unstained and epifluorescence with UV light respectively). C. Necrotic tissues are dark brown and healthy ones, green stained. D. The healthy photosynthetic tissues emit red autofluorescence, while the necrotic ones do not. E-F. Detail of the pycnidia and free pycnidiospores of Sphaerellopsis. G-H. Cross sections of the pycnidia G. Visible pycnidiospores (bright field, Toluidine blue). H. The close junction between the pycnidia and the tissues damaged by the rust can be observed (bright field, Safranin-Alcian blue). CB: bulliform cells; EB: abaxial epidermis; ED: adaxial epidermis; ES: stomata; FL: phloem; HD: short diameter vascular bundles; OS: ostiole; PC: capitate paraphysis; PF: photosynthetic parenchyma; PI: pycnidia; PIE: free pycnidiospores; PX: protoxylem; UE: urediniospore; US: uredosori. 
también indican la presencia de paráfisis capitadas rectas en el urediosoro (Melo et al., 2010; Ploetz et al., 2013; Morales \& Salazar, 2014). Aunado a los caracteres antes mencionados, el desarrollo de teliosoros hipófilos, que solo se presentan en etapas avanzadas de la infección, con escasas teliosporas de pared lisa y pedicelo persistente, son características morfológicas similares a las observadas en esta investigación para $P$. nakanishikii en las hojas de C. citratus.

En Pucciniales se ha observado la formación de la almohadilla de adhesión, que se origina en la zona de contacto entre la pared de la urediospora y las ceras epicuticulares. Esta almohadilla se aprecia como una cicatriz que refleja el contorno de la urediospora por donde se adhiere a la epidermis. Se ha indicado que previo a la inducción de la formación de esta almohadilla, las interacciones de hidrofobicidad, así como la intervención de las espinas de la pared de la urediospora son fundamentales para esta adhesión inicial (Mendgen, 1996; Clement, Porter, Butt, \& Beckett, 1994; Carver \& Gurr, 2006; Voegele et al., 2009; Voegele \& Mendgen, 2011; Serrano, Coluccia, Torres, L'Haridon, \& Métraux, 2014). Posterior a la adhesión, la almohadilla inicia su formación por la actividad de enzimas como cutinasas y lipasas liberadas por las urediosporas y la matriz extracelular que las recubre (Mendgen, 1996; Clement, Butt, \& Beckett, 1993a; Clement, Martin, Porter, Butt, \& Beckett, 1993b; Clement, Porter, Butt, \& Beckett, 1997; Carver \& Gurr, 2006; Hardham, 2007; Voegele et al., 2009; Voegele \& Mendgen, 2011; Serrano et al., 2014). En C. citratus se pudo apreciar la formación de la almohadilla de adhesión, y probablemente debido a las coincidencias en las observaciones es posible que el origen y desarrollo de esta estructura sea similar a la descrita por estos autores.

En royas se ha podido determinar que una vez que las urediosporas germinan, el tubo de germinación se desarrolla perpendicular a las células epidérmicas foliares, lo que indica la importancia de la microtopografía para determinar la dirección del crecimiento de esta estructura (Read, Kellock, Collins,
\& Gundlach, 1997; Clement, Porter, \& Beckett, 1998; Hardham, 2007; Voegele et al., 2009; Watkinson, Boddy, \& Money, 2016). Así mismo, algunos autores han indicado la degradación de las ceras epicuticulares por parte del tubo germinativo a medida que este crece y se ramifica generando mensajeros moleculares que están relacionados con el proceso de patogénesis y el bloqueo de la maquinaria de defensa de la planta (Read et al., 1997; Maheshwari, 2007; Hardham, 2007; Voegele et al., 2009; Voegele \& Mendgen, 2011; Aoun, 2017). Los hallazgos de esta investigación en relación con el desarrollo del tubo germinativo y degradación de las ceras epicuticulares por $P$. nakanishikii parasitando hojas de $C$. citratus son similares a los descritos por estos autores. No obstante, estos mismos investigadores indican la formación de un apresorio a medida que el tubo germinativo se aproxima al estoma, estructura que no se observó en esta investigación. La ausencia de esta estructura es probable se pudo deber a que, en el material analizado y fotografiado, el apresorio aún no se desarrollaba.

En la mayoría de hongos biotróficos, entre estos las royas, se ha observado que una vez que las hifas han alcanzado la cámara subestomática invaden los tejidos subyacentes, principalmente los fotosintéticos. Posteriormente, los haustorios penetran en las células de las cuales obtienen sus nutrientes provocando que éstas se vayan deteriorando progresivamente (Soto, Förster, DeMasson, \& Adaskaveg, 2005; Li et al., 2007; García et al., 2007). A medida que la infección progresa y se hace necesario una mayor cantidad de nutrientes para mantener a los urediosoros en crecimiento, la infección se expande hasta los tejidos fotosintéticos más internos, como la vaina que recubre los haces vasculares, en el caso de las gramíneas ( $\mathrm{Li}$ et al., 2007; García et al., 2007). Estos eventos relacionados con la patogénesis en la mayoría de las royas son similares a los observados en las hojas de $C$. citratus infectadas con $P$. nakanishikii. Sin embargo, en esta investigación no se observó el desarrollo de los haustorios, pero sus efectos sobre los tejidos fueron 
evidentes, resaltando principalmente el colapso y la necrosis celular.

La acumulación de polifenoles en las paredes celulares primarias o en el citoplasma es un proceso que se ha documentado como respuesta de las plantas ante la infección causada por hongos, así como por otros factores bióticos, he incluso abióticos. Se ha indicado que los polifenoles pueden reforzar las paredes celulares primarias impidiendo la penetración de los haustorios a las células y también interfieren con la germinación de las esporas (Lattanzio, Lattanzio, \& Cardinali, 2006; Aoun, Rioux, Simard, \& Bernier, 2009; Aoun, 2017). Pero dados los procesos coevolutivos, los hongos fitopatógenos han desarrollado mecanismos para desarticular esta respuesta al ataque (Dai, Andary, Cosson, \& Boubals, 1995; Aoun, 2017). En la patogénesis causada por P. nakanishikii en $C$. citratus uno de los procesos más destacados que se aprecia es la acumulación progresiva de polifenoles en tejidos, lo cual se evidenció por la extensa tinción roja en respuesta a la Safranina de las hojas atacadas, lo que termina con la muerte prematura de las hojas, lo cual es consistente con las observaciones de estos autores. La detección indirecta de polifenoles por la tinción con Safranina y otros colorantes, ha sido documentada anteriormente (O’brien \& Mccully, 1981; Ruzin, 1999)

Además de la acumulación de polifenoles, otros aspectos histopatológicos relevantes observados en $C$. citratus en respuesta a la infección por $P$. nakanishikii, se relacionan principalmente con la desorganización y el colapso progresivo de los tejidos fotosintéticos hasta la muerte de los tejidos. Adicionalmente, con la evolución de la infección, los tejidos parenquimatosos no fotosintéticos y los epidérmicos adaxiales, terminan por afectarse. Estos aspectos histopatológicos son similares a los descritos en la literatura para este tipo de organismos fitopatógenos biotróficos (Longo et al., 1997; García et al., 2007; Li et al., 2007). Así mismo, se ha documentado que en etapas avanzadas de la infección por hongos biotróficos, el floema también se ve afectado (Soto et al., 2005; Omara \& Adbelaal, 2018). Con lo cual concordamos, ya que el floema de $C$. citratus en infecciones avanzadas con $P$. nakanishikii se aprecia colapsado. Sin embargo, Omara \& Adbelaal (2018) no aprecian ningún efecto de la roya del trigo sobre el xilema, lo cual contrasta con esta investigación, se pudo observar que etapas avanzadas de la infección, el xilema se ve afectado y pierde su contorno redondeado característico, proceso que tal vez podría llevar a problemas hídricos en los tejidos. En C. citratus se observó que, por el avance progresivo de la infección y el daño celular masivo, las hojas mueren, lo cual conlleva a la defoliación y destrucción de la planta, eventos también observados por Nelson (2008) para esta misma especie.

Ma y Shang (2009) y Kang et al., (2017) indican que el daño en los tejidos del hospedante afectado por royas, se debe principalmente al deterioro de la estructura y ultraestrucrura celular como consecuencia de la desorganización y deterioro de orgánulos como mitocondrias, cloroplastos, retículo endoplasmático, núcleo y membranas celulares. Estos daños claramente afectan la homeostasis de la célula, y en consecuencia con la necrosis y muerte de células y tejidos. Aunque en esta investigación sobre el pato-sistema $C$. citratus-P. nakanishikii no se realizó observación ultraestructural por microscopía electrónica de trasmisión, es muy probable que el progresivo deterioro celular que se apreció tenga el mismo origen descrito por estos autores. También se debe tener en cuenta que los efectos histopatológicos sobre el hospedante e incluso sobre el patógeno, están afectados por las relaciones de resistencia y susceptibilidad entre planta y patógeno (compatibilidad e incompatibilidad). En este sentido, no existe información sobre estas relaciones en el pato-sistema C. citratus-P. nakanishikii.

La autofluorescencia observada de las secciones sanas y frescas de C. citratus utilizando radiación UV del material sano, muestra una fuerte señal en la longitud de onda correspondiente al rojo de los tejidos fotosintéticos y que es congruente con la fluorescencia endógena de la clorofila, indicando el buen estado fisiológico y vigor de los tejidos. Estos datos son similares a los registrados por otros autores quienes 
enfatizan la importancia de la autofluorescencia de las biomoléculas presentes en los tejidos vegetales como bioindicadores fisiológicos de salud de la planta en condiciones óptimas de desarrollo que, sin embargo, puede verse afectada cuando las plantas se enfrentan a estrés biótico o abiótico (Roshchina, 2012; García et al., 2015; Talomond, Verdeil, \& Conéjéro, 2015). Estos mismos autores indican que las biomoléculas como la cutina, las ceras epicuticulares y los compuestos polifenolicos como la lignina, pueden generar autofluorescencia en la longitud de onda azul claro cuando se irradian con luz UV. Esto se evidenció para las células epidérmicas y los tejidos esclerenquimáticos de C. citratus. Sin embargo, este mismo patrón de autofluorescencia azul claro fue patente en los tejidos con paredes primarias como el parénquima y el floema, no siendo característica común este tipo de tejidos y que podría ser causado por la presencia de ácido ferúlico que está presente en todos los tejidos de las gramíneas o también por la lignificación parcial de los tejidos parenquimatosos no fotosintéticos presentes en el mesófilo foliar (Harris \& Hartley, 1976; Lichtenthaler \& Schweiger, 1997; Hatfield, Rancour, \& Marita, 2017; Lewinsohn et al., 1998; V. Roshchina, comunicación personal, abril 2019).

Mahlein, Steiner, Hillnhütter, Dehne y Oerke (2012), Mahlein (2016) y Mahlein, Kuska, Behmann, Polder y Walter (2018), determinaron que los patrones de autofluorescencia obtenidos de los tejidos vegetales son un fenómeno complejo que depende de múltiples factores biofísicos e interacciones bioquímicas y que son fuertemente influenciados principalmente por los pigmentos presentes en el tejido, entre estos, el más importante, la clorofila. Los cambios de estos patrones de reflectancia de los tejidos pueden ser afectados durante los procesos de infección y crecimiento de los patógenos que pueden afectar la estructura o la composición química de los mismos. En este sentido los hallazgos de esta investigación concuerdan con las observaciones hechas por estos autores, ya que se evidenció la perdida de la autofluorescencia de la clorofila en la longitud de emisión correspondiente al rojo en los tejidos afectados por la infección causada por P. nakanishikii, lo cual refleja el compromiso y daño de los tejidos fotosintéticos y el afecto adverso sobre los cloroplastos durante el proceso de patogénesis. El efecto de los patógenos biotróficos como las royas sobre la fotosíntesis y los contenidos de clorofila, han sido observados en varios grupos de plantas, incluidas las gramíneas (Scholes \& Rolfe, 2009; Zhao, Glynn, Glaz, Comstock, \& Sood, 2011; Abdulbagiyeva, Zamanov, Talai, \& Allahverdiyev, 2015; Walters, 2015). Es interesante indicar que en $C$. citratus los tejidos parenquimatosos de pared primaria de las regiones afectadas por la necrosis celular debido al desarrollo de la roya pierden la autofluorescencia azul claro característica y que probablemente se puede atribuir a la lignificación parcial y/o la presencia de ácido ferúlico en estas células; reflejando el efecto del patógeno sobre este tipo de moléculas presentes en la pared celular (Mahlein et al., 2018).

Sphaerellopsis filum (Biv. ex Fr.) B. Sutton es una especie registrada como un hiperparásito que está asociado con unas 369 especies de royas que parasitan principalmente los urediosoros y ocasionalmente los teliosoros. Sphaerellopsis filum es observado comúnmente como anamorfo que produce picnidios oscuros erupentes de ostiolo central, con picnidiosporas hialinas de paredes lisas y de contorno fusiforme. Los picnidios se encuentran unidos estrechamente a los urediosoros en donde parasitan las hifas que dan sustento al mismo (Yuan, Pei, Hunter, \& Royle, 1998; Płachecka, 2005; Trakunyingcharoen, et al., 2014). Todas estas observaciones registradas por estos autores son congruentes a lo observado para el hiperparásito en los urediosoros de $P$. nakanishikii en las hojas de C. citratus, los datos morfológicos observados sugieren su circunscripción taxonómica. Sin embargo, para aclarar esta situación, sería necesario hacer investigaciones enfocadas al cultivo del hiperparásito para observar otros 
caracteres morfológicos de importancia taxonómica posterior corroboración molecular.

Declaración de ética: los autores declaran que todos están de acuerdo con esta publicación y que han hecho aportes que justifican su autoría; que no hay conflicto de interés de ningún tipo; y que han cumplido con todos los requisitos y procedimientos éticos y legales pertinentes. Todas las fuentes de financiamiento se detallan plena y claramente en la sección de agradecimientos. El respectivo documento legal firmado se encuentra en los archivos de la revista.

\section{AGRADECIMIENTOS}

Los autores agradecen a las siguientes instituciones: al laboratorio de Investigación e Innovación en Biotecnología Agroambiental (LIIBAAM) de la Universidad de Santander (UDES), al Laboratorio de Biotecnología de la Universidad de Antioquia (UdeA) por su apoyo en la visualización de las muestras en microscopía fotónica, al Laboratorio de Microscopía Electrónica de Barrido, Universidad Nacional Autónoma de México (UNAM) por la ayuda con las imágenes en SEM. También a Roberto Enrique Llanos-Romero del Laboratorio de Química. Departamento de ecología y recursos naturales. Facultad de Ciencias, (UNAM) por su ayuda con las secciones bilingües del manuscrito. A Victoria Vladimirovna Roshchina del Institute of Cell Biophysics of Russian Academy of Sciences, Pushchino, Russia, Laboratory of Microspectral Analysis of Cells and Cellular Systems por sus valiosos comentarios sobre la presencia del acido Ferúlico en granmíneas y a Mauricio Alberto Salazar Yepes Universidad Nacional de ColombiaSede Medellin por sus acertados comentarios al manuscrito.

\section{RESUMEN}

Introducción: Los aspectos histopatológicos e histoquímicos relacionados con el ataque de royas en plantas, así como su relación con los diferentes estados espóricos, son escasos en la literatura científica. Objetivos: describir y analizar los aspectos histopatológicos e histoquímicos en Cymbopogon citratus y su relación con los diferentes estados espóricos de la roya Puccinia nakanishikii. Métodos: durante abril y agosto 2013 se recolectaron hojas sanas e infectadas con Puccinia nakanishikii en la escarpa noroccidental de la meseta de Bucaramanga-Colombia. Las muestras con lesiones en diferentes etapas del desarrollo se fijaron y procesaron de acuerdo a protocolos estándar para la inclusión y corte en parafina y resina. Las secciones obtenidas en parafina $(5-7 \mu \mathrm{m})$ fueron teñidas con Safranina-azul de Alcian y azul de Alcian-Hematoxilina. En tanto que las secciones obtenidas en resina $(0.5 \mu \mathrm{m})$ se tiñeron con azul de Toluidina. También se elaboraron secciones a mano alzada para análisis de autofluorescencia. Las observaciones y registro fotográfico se efectuaron con microscopio fotónico y microscopía de epifluorescencia. Para observaciones con microscopía electrónica de barrido (MEB), las muestras se fijaron en Glutaraldehído, se deshidrataron con 2,2 dimetoxipropano, se desecaron a punto crítico y se metalizaron con oro. Resultados: las hojas son por lo general hipostomáticas, con células epidérmicas largas y cortas formando filas paralelas y con la presencia de tricomas unicelulares espinosos y microtricomas. La superficie abaxial está cubierta por una densa capa de ceras epicuticulares y la adaxial está formada por agrupaciones de células buliformes y células epidérmicas de contorno rectangular o cuadrado. En el mesófilo no hay diferenciación entre parénquima de empalizada y esponjoso y su anatomía refleja el metabolismo $\mathrm{C}_{4}$ presente en esta gramínea. Se observó la formación de urediosoros y teliosoros hipófilos. Las urediosporas son la fase de reinfección y estas tienen de 4-5 poros germinativos ecuatoriales y su pared es equinulada. Las teliosporas son de pared lisa y de pedicelo persistente. Las urediosporas forman tubos de geminación por lo general sobre la superficie abaxial de la hoja y se desarrollan en dirección de los estomas, por donde penetran al interior del mesófilo. No se observó la presencia de apresorios. La epidermis se desprende y levanta por del desarrollo de las urediosporas y las paráfisis capitadas, a medida que el urediosoro crece. Con el avance de la infección, los tejidos fotosintéticos se desorganizan, pierden la autofluorescencia de la clorofila y las células sufren necrosis. Posteriormente, los tejidos vasculares se fragmentan y colapsan. Para este momento, la infección se ha extendido sobre toda la lámina foliar llevando a la muerte de la hoja y defoliación de la planta. Durante etapas avanzadas de la infección en los urediosoros se observaron picnidios, probablemente del hiperparásito Sphaerellopsis, asociados estrechamente a los tejidos infectados por la roya. Conclusiones: Puccinia nakanishikii se desarrolla sobre las hojas de Cymbopogon citratus produciendo urediosoros y teliosoros. Las urediosporas son la fase de reinfección, y las teliosporas solo se observaron en etapas avanzadas de la infección. La epidermis y los tejidos fotosintéticos son severamente afectados por la necrosis celular. En etapas avanzadas de la infección los tejidos vasculares se ven afectados. 
Palabras clave: alteraciones histopatológicas, royas, teliosporas, ultrastructura, urediniosporas.

\section{REFERENCIAS}

Abdulbagiyeva, S., Zamanov, A., Talai, J., \& Allahverdiyev, T. (2015). Effect of rust diseaseon photosynthetic rate of wheat plant. Journal of Agricultural Science andTechnology B, 5, 486-490.

Agrios, G. N. (2005). Plant pathology (5 ${ }^{\text {th }}$ Ed.). San Diego, USA: Academic Press Inc.

Aoun, M. (2017). Host defense mechanisms during fungal pathogenesis and how these are overcome in susceptible plants: A review. International Journal of Botany, 13, 82-102.

Aoun, M., Rioux, D., Simard, M., \& Bernier, L. (2009). Fungal colonization and host defense reactions in Ulmus americana callus cultures inoculated with Ophiostoma novo-ulmi. Phytopathology, 99, 642-650.

Bender, C. M., Pretorius, Z. A., Kloppers, F. J., \& Spies, J. J. (2000). Histopathology of leaf rust infection and development in wheat genotypes containing Lr12 and Lr13. Journal of Phytopathology, 148(2), 65-76.

Bertea, M. C., Tesio, M., D’agostino, G., Buffa, G., Camusso, W., Bossi, S., Mucciarelli, M., Scannerini, S., \& Maffei, M. (2003). The C 4 biochemical pathway and the anatomy of lemongrass (Cymbopogon citratus (DC) Stapf.) cultivated in temperate climates. Plant Biosystems, 137(2), 175-184.

Bertea, M. C., \& Maffei, M. E. (2010). The genus Cymbopogon botany, including anatomy, physiology, biochemistry, and molecular biology. In A. Akhila (Ed.), Essential Oil- Bearing Grasses: The genus Cymbopogon (pp. 1-24). Boca Raton, USA: CRC Press.

Bhattacharya, S. (2017). Wheat rust back in Europe. Nature, 542, 145-146.

Buckley, T. N., Sack, L., \& Gilbert, M. E. (2011). The role of bundle sheath extension and life form in stomatal responses to leaf water status. Plant Physiology, 156, 962-973.

Buriticá, P. (1978). Los hongos de Colombia II: Nuevas especies de uredinales. Caldasia, 12(57), 165-170.

Buriticá, P. (1991). Familias del orden Uredinales con ciclo de vida completamente reducido. Revista de la Academia Colombiana de Ciencias Exactas Físicas y Naturales, 18(69), 131-148.

Buriticá, P. (2001). Descubriendo ancestros de uredinales. Revista de la Academia Colombiana de Ciencias Exactas Físicas y Naturales, 25(96), 395-401.
Buriticá, P. (2003). Estado del conocimiento universal sobre el orden Uredinales. (Fungi, royas). Revista Facultad Nacional de Agronomía Medellín, 56(1), 1813-1838.

Buriticá, P., \& Pardo, V. M. (1996). Flora uredineana colombiana. Revista de la Academia Colombiana de Ciencias Exactas Físicas y Naturales, 20(77), 183-236.

Buriticá, P., \& Salazar, M. A. (2007). Nuevos registros de royas (Uredinales) potencialmente importantes en Colombia. Revista Facultad Nacional de Agronomía Medellin, 60(1), 3645-3655.

Buriticá, C. P., Salazar, Y. M., \& Pardo, C. V. M. (2014). Pucciniales (Fungi), royas de Colombia. Revista Facultad Nacional de Agronomía, Medellín, 67(Suplemento 1), 1-93.

Carris, L. M., \& Littlefield, L. J. (2017). Rust and smut diseases. In B. H. Ownley \& R. N. Trigiano (Eds.), Plant Pathology Concepts and Laboratory Exercises (3 ${ }^{\text {th }}$ Ed., pp. 221-236). Boca Raton, Florida: CRC Press Taylor \& Francis Group.

Carver, T. L. W., \& Gurr, S. J. (2006). Filamentous fungi on plant surfaces. Annual Plant Reviews, 23, 368- 397.

Chardón, C. E., \& Toro, R. A. (1930). Mycological explorations of Colombia. Journal of the Department of Agriculture of Porto Rico, 14(4), 195-301.

Clement, J. A., Butt, T. M., \& Beckett, A. (1993a). Characterization of the extracellular matrix produced in vitro by urediniospores and sporelings of Uromyces viciaefabae. Mycological Research, 97, 594-602.

Clement, J. A., Martin, S. G., Porter, R., Butt, T. M., \& Beckett, A. (1993b). Germination and the role of extracellular matrix in adhesion of urediniospores of Uromyces viciae-fabae to synthetic surfaces. Mycological Research, 97, 585-593.

Clement, J. A., Porter, R., Butt, T. M., \& Beckett, A. (1994). The role of hydrophobicity in attachment of urediniospores and sporelings of Uromyces viciaefabae. Mycological Research, 98, 1217-1228.

Clement, J. A., Porter, R., Butt, T. M., \& Beckett, A. (1997). Characteristics of adhesion pads formed during imbibition and germination of urediniospores of Uromyces viciaefabae. Mycological Research, 101, 1445-1458.

Clement, J. A., Porter, R., \& Beckett, A. (1998). The orientation of urediniospores of Uromyces viciae-fabae during fall and after landing. Mycological Research, 102, 907-913.

Cummins, G. (1971). The rust fungi of cereals, grasses and bamboos. Nueva York, USA: Springer-Verlag. 
Cummins, G., \& Hiratsuka, Y. (2003). Illustrated general of rust fungi ( $3^{\text {rd }}$ Ed.). San Pablo, USA: The American Phytopathological Society.

Dai, G. H., Andary, C., Mondolot-Cosson, L., \& Boubals, D. (1995). Histochemical studies on the interaction between three species of grapevine, Vitis vinifera, $V$. rupestris and $V$. rotundifolia and the downy mildew fungus, Plasmopara viticola. Physiological and Molecular Plant Pathology, 46, 177-188.

Dixon, L. J., Castlebury, L. A., Aime, M. C., Glynn, N. C., \& Comstock, J. C. (2010). Phylogenetic relationships of sugarcane rust fungi. Mycological Progress, 9, 459-468.

Doohan, F., \& Zhou, B. (2018). Fungal pathogens of plants. In K. Kavanagh (Ed.), Fungi biology and applications ( $3^{\text {rd }}$ Ed., pp. 355-386). County Kildare, Ireland: John Wiley \& Sons, Inc.

Eltahir, S. A., \& Abuereish, I. B. (2010). Leaf and stem anatomy of Cymbopogon citratus and Cymbopogon schoenanthus in Sudan. Journal of Chemical and Pharmaceutical Research, 2(4), 766-771.

Epstein, A. H., Simons, M. D., Frey, K. J., \& Rothman, P. (1998). Field resistance of oats to Puccinia graminis f. sp. avenae measured via yield and seed weight reduction. Plant Disease, 72, 154-156.

Eversmeyer, M. G., \& Kramer, C. L. (2000). Epidemiology of wheat leaf and stem rust in the central great plains of the USA. Annual Review of Phytopathology, 38, 491-513.

García, G. D., Buriticá, P., \& Henao, M. L. M. (2007). Elementos para la elaboración del libro rojo de hongos royas de Colombia. Revista de la Academia Colombiana de Ciencias Exactas Físicas y Naturales, 31(121), 449-468.

García, L. E., Leyva, M. S. G., Cárdenas, S. E., Huerta, E. J., Sandova, I. S., \& Villaseñor, M. E. (2007). Proceso de infección de la roya de la hoja del trigo (Puccinia triticina erikson) en genotipos con resistencia parcial. Agrociencia, 41, 775-785.

García, P. J. I., Fernández, M. B., Duke, O. E., Hernández, A., López, A. F., \& Becerril, J. M. (2015). Autofluorescence: biological functions and technical applications. Plant Science, 236, 136-145.

Gardner, E. D. (1985). Lemongrass Rust Caused by Puccinia nakanishikii in Hawaii. Plant Disease, 69, 1100.

Guerra, M., Rodríguez, M., García, G., \& Rangel, C. (2004). Actividad antimicrobiana del aceite esencial y crema de Cymbopogon citratus (DC), Stapf. Revista Cubana de Plantas Medicinales, 9, 1-6.

Grass Phylogeny Working Group II (GPWG). (2012). New grass phylogeny resolves deep evolutionary relationships and discovers $\mathrm{C} 4$ origins. New Phytologist, 193, 304-312.

Haque, A. M. N. A., Remadevi, R., \& Naebe, M. (2018). Lemongrass (Cymbopogon): a review on its structure, properties, applications and recent developments. Cellulose, 25(10), 5455-5477.

Hardham, A. R. (2007). Cell biology of fungal and Oomycete infection of plants. In K. Esser (Ed.), The Mycota. Biology of the fungal cell VIII ( $2^{\text {nd }}$ Ed., pp. 251-289). Berlin, Germany: Springer-Verlag.

Hatfield, D. R., Rancour, M. D., \& Marita, M. J. (2017). Grass cell walls: a story of cross linking. Frontiers in Plant Science, 7, 1-15.

Harris, P. J., \& Hartley, R. D. (1976). Detection of bound ferulic acid in cell walls of the gramineae by ultraviolet fluorescence microscopy. Nature, 259, 508-510.

Hawksworth, D. L., \& Lücking, R. (2017). Fungal diversity revisited: 2.2 to 3.8 million species. Microbiology Spectrum, 5(4), 1-17.

Hernandez, J. R., \& Hennen, J. F. (2003). Rust fungi causing galls, witches' brooms, and other abnormal plant growths in northwestern Argentina. Mycologia, 95(4), 728-755.

Hiratsuka, Y., \& Hiratsuka, N. (1980). Morphology of spermogonia and taxonomy of rust fungi. Reports of the Tottori Mycological Institute, 18, 257-268.

Jiang, X. L., \& Kang, Z. S. (2010). Ultrastructural changes in the interaction between Puccinia striiformis and wheat cultivar with slow-rusting resistance. Agricultural Sciences in China, 9(1), 64-70.

Kang, Z., Tang, C., Zhao, J., Cheng, Y., Liu, Y., Guo, J., Wang, X., \& Chen, X. (2017). WheatPuccinia striiformis interactions. In X. Chen \& Z. Kang (Eds.), Stripe rust (pp. 155-183). Dordrecht, The Netherlands: Springer.

Kellogg, A. E. (2015). The families and genera of vascular plants. volume XIII. Flowering plants. Monocots. Poaceae. Heidelberg, Germany: Springer International Publishing.

Kloppers, F. J., \& Pretorius, Z. A. (1995). Histology of the infection and development of Puccinia recondita $\mathrm{f}$. sp. tritici in a wheat line with Lr37. Journal of Phytopathology, 143(5), 261-267.

Koike, S. T., \& Molinar, R. H. (1999). Rust Disease on Lemongrass in California. Plant Disease, 83(3), 304.

Kolmer, J. A., Ordonez, M. E., \& Groth, J. V. (2009). The rust fungi. In Encyclopedia of Life Sciences (ELS) (pp. 1-8). John Wiley \& Sons, Ltd: Chichester.

Lattanzio, V., Lattanzio, M. T. V., \& Cardinali, A. (2006). Role of phenolics in the resistance mechanisms of 
plants against fungal pathogens and insects. In F. Imperato (Ed.), Phytochemistry: advances in research (pp. 23-67). Trivandrum, India: Research Signpost.

Leyva, M. S. G., Espitia, R. E., Villaseñor, M. H. E., \& Huerta, E. J. (2004). Pérdidas ocasionadas por Puccinia graminis f. sp. avenae Eriks. y Henn., Causante de la roya del tallo en seis cultivares de avena (Avena sativa $\mathrm{L}$.) en los valles altos de México. Revista Mexicana de Fitopatología, 22(2), 166-171.

Lewinsohn, E., Dudai, N., Tadmor, Y., Katzir, I., Ravid, U., Putievsky, E., \& Joel, M. D. (1998). Histochemical localization of Citral accumulation in lemongrass leaves (Cymbopogon citratus (DC.) Stapf. Poaceae). Annals of Botany, 81, 35-39.

Lichtenthaler, K. H., \& Schweiger, J. (1997). Cell wall bound ferulic acid, the major substance of the bluegreen fluorescence emission of Plants. Journal of Plant Physiology, 52, 272-282.

Li, Y. M., Windham, M. T., \& Trigiano, R. N. (2007). Microscopic and macroscopic studies of the development of Puccinia hemerocallidis in resistant and susceptible daylily cultivars. Plant Disease, 91(6), 664-668.

Lin, C. H., Falk, R. H., \& Stocking, C. R. (1977). Rapid chemical dehydration of plant material for light and electron microscopy with 2,2-dimethoxypropane and 2,2-diethoxypropane. American Journal of Botany, 64(5), 602-605.

Longo, N., Naldini, B., Paolillo, A., Drovandi, F., Tani, G., \& Gonnelli, T. (1997). Morphological aspects of early host-parasite interactions in infections of Melampsora pinitorqua and Melampsora larici-tremulae on Pinus sylvestris: Implications in the taxonomical relationship of the two rust fungi. Caryologia, 50(1), 37-57.

Lundgren, R. M., Osborne, P. C., \& Christin, A. P. (2014). Deconstructing Kranz anatomy to understand C4 evolution. Journal of Experimental Botany, 65(13), 3357-3369.

Ma, Q., \& Shang, S. H. (2009). Ultrastructure of stripe rust (Puccinia striiformis f. sp. tritici) interacting with slow-rusting, highly resistant, and susceptible wheat cultivars. Journal of Plant Pathology, 91(3), 597-606.

Maheshwari, R. A. (2007). Scourge of mankind: From ancient times into the genomics era. Current Science, 93(9), 1249-1256.

Mahlein, K. A. (2016). Plant disease detection by imaging sensors-parallels and specific demands for precision agriculture and plant phenotyping. Plant disease, $100(2), 241-251$.

Mahlein, K. A., Steiner, U., Hillnhütter, C., Dehne, W. H., \& Oerke, C. E. (2012). Hyperspectral imaging for small-scale analysis of symptoms caused by different sugar beet diseases. Plant Methods, 8(3), 1-13.

Mahlein, K. A., Kuska, T. M., Behmann, J., Polder, G., \& Walter, A. (2018). Hyperspectral sensors and imaging technologies in phytopathology: state of the art. The Annual Review of Phytopathology, 56, 535-558.

Maier, W., Begerow, D., Wei, M., \& Oberwinkle, R. F. (2003). Phylogeny of the rust fungi: an approach using nuclear large subunit ribosomal DNA sequences. Canadian Journal of Botany, 81(1), 12-23.

Mayor, E. (1913). Contribution a l'etude de Uredinées de Colombie. Mémoires de la Société Neuchateloise de Sciences Naturelles, 5, 442-509.

Melo, P., Araújo, J., Carvalho, A., Tostes, G., \& Areâs, M. (2010). Puccinia nakanishikii, nova ocorrência de ferrugem em capim-limão (Cymbopogon citratus) no Brasil. Tropical Plant Pathology, 35(2), 129-130.

Mendgen, K. (1996). Fungal attachment and penetration. In G. Kerstiens (Ed.), Plant cuticles (pp. 175-188). Oxford, England: Garland Science.

Mendgen, K., \& Hahn, M. (2002). Plant infection and the establishment of fungal biotrophy. Trends in Plant Science, 7(8), 352-356.

Metcalfe, C. R. (1960). Anatomy of the Monocotyledons I: Gramineae ( $1^{\text {St }}$ Ed.). New York, USA: Oxford Clarenden Press.

Moldenhauer, J., Moerschbacher, B. M., \& Westhuizen, A. J. (2006). Histological investigation of stripe rust (Puccinia striiformis f.sp. tritici) development in resistant and susceptible wheat cultivars. Plant Pathology, 55(4), 469-474.

Morales, L. Á., \& Salazar, Y. M. (2014). Caracterización morfológica de las royas (Pucciniales) que afectan el limoncillo (Cymbopogon citratus (dc.) stapf) en Colombia. Bioagro, 26(3), 171-176.

Nelson, S. (2008). Rust of lemongrass. Plant Disease, 57, $1-5$.

Negrelle, R., \& Gómez, E. (2007). Cymbopogon citratus (DC.) Stapf: Chemical composition and biological activities. Revista Brasileira de Plantas Medicinais, 9(1), 80-92.

O'brien, T. P., \& Mccully, M. E. (1981). The study of plant structure principles and selected methods. Melbourne, Australia: Termarcarphy Pty. Ltd.

Omaraa, I. R., Khaled, A. A., \& Abdelaal, A. A. K. (2018). Biochemical, histopathological and genetic analysis associated with leaf rust infection in wheat plants (Triticum aestivum L.). Physiological and Molecular Plant Pathology, 104, 48-57. 
Pavgi, M. S. (1972). Morphology and taxonomy of the Puccinia species on corn and Sorghum. Mycopathologia et Mycologia Applicata, 47(3), 207-220.

Pardo, V. M. (1998). Registros nuevos para la flora de uredinales (royas) de Colombia. Revista de la Academia Colombiana de Ciencias Exactas Físicas y Naturales, 22(84), 347-354.

Pardo, V. M. (1999). La roya del limoncillo, una nueva enfermedad para Colombia y Sudamérica. Fitopatología Colombiana, 3(1), 43-44.

Pardo, V. M. (2003). Nuevas especies y registros de uredinales para Colombia y Sudamérica. Caldasia, 25(2), 283-296.

Pareek, S. K., \& Gupta, R. (1985). On the status of agronomic research in Cymbopogon grasses in India with projections on future work. India, 29, 215-224.

Płachecka, A. (2005). Microscopical observations of Sphaerellopsis filum, a parasite of Puccinia recondita. Acta Agrobotanica, 58(1), 67-7.

Ploetz, C. R., Palmateer, J. A., Lopez, P., \& Aime, C. M. (2013). First Report of Rust Caused by Puccinia nakanishikii on Lemongrass, Cymbopogon citratus, in Florida. Plant Disease, 98(1), 156

Read, D. N., Kellock, J. L., Collins, J. T., \& Gundlach, M. A. (1997). Role of topography sensing for infectionstructure differentiation in cereal rust fungi. Planta, 202(2), 163-170.

Roshchina, V. V. (2012). Vital autofluorescence: application to the study of plant living cells. International Journal of Spectroscopy, 2012, 1-14.

Ruzin, S. E. (1999). Plant microtechnique and microscopy. Nueva York, USA: Oxford University.

Salazar, Y. M., \& Buriticá, C. P. (2003). Uredobiota de la familia Poaceae en la zona cafetera colombiana. Revista Cenicafé, 5(4), 329-346.

Salazar, M. A., \& Buriticá, C. P. (2004). Nuevos registros para la Uredobiota colombiana (Fungi, Uredinales). Caldasia, 26(1), 79-87.

Salazar, M. A., \& Buriticá, C. P. (2008). Nuevas especies para la Uredobiota Neotropical. Revista Facultad Nacional de Agronomía Medellín, 6(1), 4291-4301.

Salazar, M. A., Buriticá, C. P., \& Cadena, C. G. (2002). Implicaciones de los estudios sobre biodiversidad de los Uredinales (royas) en la región cafetera colombiana. Revista Cenicafé, 53(3), 219-238.

Savile, D. B. O. (1984). Taxonomy of the cereal rust fungi. In W. R. Bushnell \& A. P. Roelfs (Eds.), The cereal rusts, Origins, specificity, structures, and physiology (pp. 79-112). Florida, USA: Academic Press.
Serrano, M., Coluccia, F., Torres, M., L'Haridon, F., \& Métraux, P. J. (2014). The cuticle and plant defense to pathogens). Frontiers in Plant Science, 1(274), 1-8.

Schumann, G. L., \& D'Arcy, C. J. (2009). Essential plant pathology (2 ${ }^{\text {nd }}$ Ed.). Minnesota, USA: American Phytopathological Society.

Scot, N. (2008). Rust of lemongrass. Hawaii, USA: College of Tropical Agriculture and Human Resources.

Scholes, D. J., \& Rolfe, A. S. (2009). Chlorophyll fluorescence imaging as tool for understanding the impact of fungal diseases on plant performance: a phenomics perspective. Functional Plant Biology, 36, 880-892.

Serrato, C. A., \& Moreno, B. A. M. (2003). Efecto del abono orgánico y de la edad del corte en la producción de biomasa y de aceite esencial de limoncillo. Revista Cenicafé, 54(4), 273-277.

Shah, G., Kaur, M., Dhabiliya, F., \& Shri, R. (2012). Pharmacognostic standardization of Cymbopogon citratus (dc.) stapf leaves. Pharmacognosy Journal, 4(22), 19-25

Singh, R. P., Hodson, D. P., Huerta-Espino, J., Jin, Y., Njau, P., Wanyera, R., ... Ward, R. W. (2008). Will stem rust destroy the world's wheat crop? In D. L. Sparks (Eds.), Advances in Agronomy (Vol. 98, pp. 271-309). Newark, USA: Academic Press.

Singh, R. P., Singh, P. K., Rutkoski, J., Hodson, D. P., He, X., Jørgensen, L. N., \& Huerta-Espino, J. (2016). Disease impact on wheat yield potential and prospects of genetic control. The Annual Review of Phytopathology, 54, 303-322.

Soto, O. R., Vega, M. G., \& Tamajón, N. A. L. (2002). Instructivo técnico del cultivo de Cymbopogon citratus (D.C) Stapf (caña santa). Revista Cubana de Plantas Medicinales, 7(2), 89-95.

Soto, E. A., Förster, H., DeMason, A. D., \& Adaskaveg, E. J. (2005). Initial infection and colonization of leaves and stems of cling peach by Tranzschelia discolor. Phytopathology, 5(8), 942-950.

Srivastava, R. C., \& Abraham, J. (1977). Anatomical studies on abnormal growth caused by Puccinia ruelliae Syd. on Ruellia prostrata. Mycopathologia, 62(2), 113-116.

Staples, R. C. (2000). Research on the rust fungi during the twentieth century. Annual Review of Phytopathology, 38, 49-69.

Talamond, P., Verdeil, J. L., \& Conéjéro, G. (2015). Secondary metabolite localization by autofluorescence in living plant cells. Molecules, 20(3), 5024-5037.

Torres, B. M. R., Silva, M. M., Nogueira, G., Alvarenga, A., \& Silva, P. S. (2016). Occurrence of homobaric and heterobaric leaves in two forest types of southern Brazil. Acta Botanica Brasilica, 30(2), 304-312. 
Trakunyingcharoen, T., Lombard, L., Groenewald, Z. J., Cheewangkoon, R., Toanun, C., Alfenas, C. A., \& Crous, W. P. (2014). Mycoparasitic species of Sphaerellopsis, and allied lichenicolous and other genera. IMA Fungus, 5(2), 391-414.

Vida, J., Carvalho, J. A. A., \& Verzignassi, J. R. (2006). Primeira ocorrência de ferrugem em capim-limão causada por Puccinia cymbopogonis no Brasil. Summa Phytopathologica, 32(1), 89-91.

Voegele, R. T., Hahn, M., \& Mendgen, K. (2009). The Uredinales: cytology, biochemistryand molecular biology. In K. Esser \& H. B Deising (Eds.), The Mycota. A Comprehensive Treatise on Fungi as Experimental Systems for Basic and Applied Research (pp. 69-98). Berlin, Alemania: Springer-Verlag.

Voegele, R. T., \& Mendgen, K. W. (2011). Nutrient uptake in rust fungi: how sweet is parasitic life? Euphytica, $179,41-55$

Wahyuno, D., \& Kakishima, M. (2015). Aecidium cinnamomi (Uredinales) has an endocyclic life cycle on Cinnamomum spp. (Lauraceae) in Indonesia. Australasian Plant Disease Notes, 10(154), 1-4.

Walters, R. D. (2015). Physiological responses of plants to attack. Oxford, England: John Wiley \& Sons, Ltd.

Watkinson, C. S., Boddy, L., \& Money, P. N. (2016). The fungi. Oxford, London: Academic Press.
Webster, J., \& Weber, W. S. (2007). Introduction to Fungi ( $3^{\text {rd }}$ Ed.). Cambridge, England: Cambridge University Press.

Wesp, G. C., Martinelli, J. A., Graichen, S. F. A., \& Soares, C. M. (2013). Histopathology of durable adult plant resistance to leaf rust in the Brazilian wheat variety Toropi. The European Journal of Plant Pathology, 137(1), 181-196.

Yeung, E. C. T., Stasolla, C., Sumner, M. J., \& Huang, B. Q. (2015). Plant microtechniques and protocols. New York, USA: Springer.

Yuan, W. Z., Pei, H. M., Hunter, T., \& Royle, J. (1998). Eudarluca caricis, the teleomorph of the mycoparasite Sphaerellopsis filum, on blackberry rust Phragmidium violaceum. Mycological Research, 102(7), 866-868.

Zhao, D., Glynn, C. N., Glaz, B., Comstock, C. J., \& Sood, S. (2011). Orange rust effects on leaf photosynthesis and related characters of sugarcane. Plant Disease, 95(6), 880-892.

Zuluaga, M. C., Buriticá, C. P., \& Marín, M. M. (2009). Generalidades de los Uredinales (Fungi: Basidiomycota) y de sus relaciones filogenéticas. Acta Biológica Colombiana, 14(1), 39-54.

Zuluaga, C., Buriticá, P., \& Marín, M. (2011). Filogenia de los hongos roya (Uredinales) en la zona andina colombiana mediante el uso de secuencias del ADN ribosomal 28S. Revista de Biología Tropical, 59(2), 517-540. 